\title{
1,3-氨基醇的合成研究进展
}

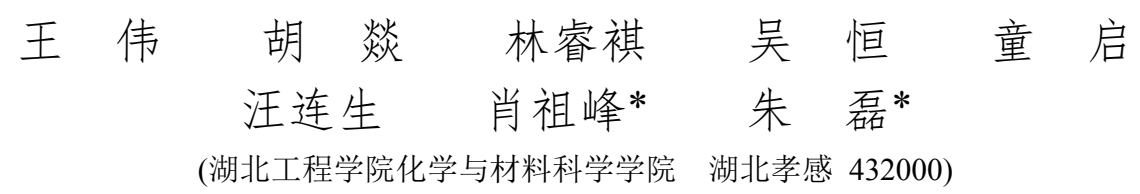

\begin{abstract}
摘要 具有光学活性的 1,3-氨基醇既是有机化学中重要的合成砌块，也是众多生物活性分子的核心结构, 因此不对称 合成 1,3-氨基醇一直是合成领域的一个热点. 从 aldol 缩合或 $a z o$-aldol 缩合合成, 过渡金属催化 $\mathrm{C}-\mathrm{H}$ 键活化、氨化合 成, 氮杂环的开环-加成合成, $[3+2]$ 偶极环加成反应等方面综述了近年来所发展的 1,3 -氨基醇的合成方法及进展.

关键词 1,3-氨基醇; 不对称合成; 催化剂
\end{abstract}

\section{Progress on the Synthesis of 1,3-Amino Alcohol}

\author{
Wang, Wei Hu, Yi Lin, Ruiqi Wu, Heng Tong, Qi \\ Wang, Liansheng Xiao, Zufeng* Zhu, Lei* \\ (School of Chemistry and Material Science, Hubei Engineering University, Xiaogan, Hubei 432000)
}

\begin{abstract}
Optically pure 1,3-amino alcohol is not only the important synthon in organic synthesis, but also the core structure of numerous bioactive molecule. As a result, the formation of 1,3-amino alcohols occupies a hot resarch topic in asymmetric synthesis. This review symmarizes several types of frequently-used methods and progress on synthesizing 1,3-amino alcohols: aldol or azo-aldol condensation synthesis, transition metal catalyzed $\mathrm{C}-\mathrm{H}$ activation and amination synthesis, ring-opening and addition of azocyclic compounds, and [3+2] dipolar-cycloaddition reaction etc.
\end{abstract}

Keywords 1,3-amino alcohol; asymmetric synthesis; catalyst

1,3-氨基醇骨架结构的机化合物广泛存在于天然产 物及生物活性分子结构中 ${ }^{[1]}($ Scheme 1), 该类化合物是 医药化学中的有效中间体, 为医药开发提供了大量研究 素材. 同时, 1,3-氨基醇的两个杂原子 $(\mathrm{N}, \mathrm{O})$ 具有较高的 灵活性, 可以用一个或者两个杂原子与路易斯酸、过渡 金属或者非手性的底物成键连接, 在不对称合成中有着 广泛的应用 ${ }^{[2]}$, 如羰基的不对称还原和加成、不对称 Diels-Alder 环加成反应、不对称 1,3-偶极环加成反应、 Heck 反应等. 因此如何简洁高效地合成 1,3-氨基醇是有 机化学研究的重要内容之一.

目前 1,3-氨基醇的有效合成方法可以分为以下几 类: (1)由 aldol 缩合或 $a z o$-aldol 缩合反应进行合成; (2)由过渡金属催化 $\mathrm{C}-\mathrm{H}$ 键活化、氨化反应进行合成;
(3)利用氮杂环的开环-加成反应进行合成; (4)利用 $[3+$ 2]偶极环加成合成及其他方法(Scheme 2).

上述各合成方法中, $\beta$-氨基醛/酮/酯、异㤠唑烷、 1,3 噁嗪烷/酮等化合物可分别通过简单的加成/还原 ${ }^{[3]}$ 或水 解 ${ }^{[4]}$ 等方法制备 1,3 -氨基醇, 因此本文将上述化合物的 合成均归于 1,3 -氨基醇的合成. 本文将分别介绍各类方 法的底物适用范围，并将部分方法在生物活性分子合成 中的应用进行综述.

\section{1,3-氨基醇类化合物的不对称合成}

\section{1 aldol 缩合或 azo-aldol 缩合反应}

Aldol 缩合或 $a z o$-aldol 缩合反应在过去几十年取得 了长足进展，通过底物手性诱导或手性有机小分子催化

\footnotetext{
* Corresponding authors. E-mail: lei.zhu@hbeu.edu.cn; chemhbeu@163.com

Received November 6, 2019; revised December 11, 2019; published online January 21, 2020.

Project supported by the Hubei Provincial Education Department Young and Middle-aged Talents Project (No. Q20172705), the National Natural Science Foundation of China (No. 21774029), and the Hubei University Excellent Young and Middle-aged Science and Technology Innovation Team Project (No. T201816).

湖北省教育厅中青年人才(No. Q20172705)、国家自然科学基金(No. 21774029)、湖北省高等学校优秀中青年科技创新团队计划(No. T201816)资助项 目.
} 
<smiles>CC(=O)CC1CCCC(CC(O)c2ccccc2)N1CO</smiles><smiles>CC1=CC(=O)OC(CC2CCCCN2C)C1</smiles>

Dumetorine<smiles>C[C@@H](O)CC1CCCCN1</smiles>

$( \pm)$-Sedridine

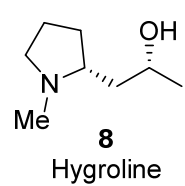<smiles>[R]N1CCCCC1CC(O)c1ccccc1</smiles>

$3( \pm)$-Norsedamine $\mathrm{R}=\mathrm{H}$

$4( \pm)$-Sedamine $\mathrm{R}=\mathrm{Me}$

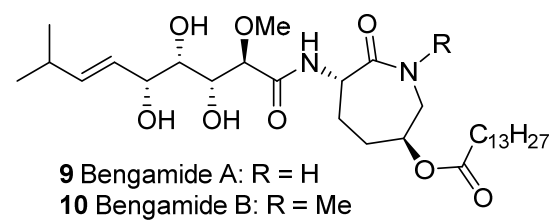

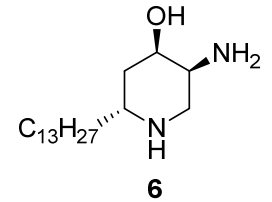

$( \pm)$-Tetrahydropseudistomin

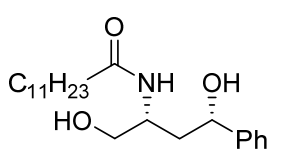

$11(-)-H P A-12$

图式 1 几种含 1,3-氨基醇结构的生物活性分子

Scheme 1 Several bioactive molecules based on 1,3-amino alcohol

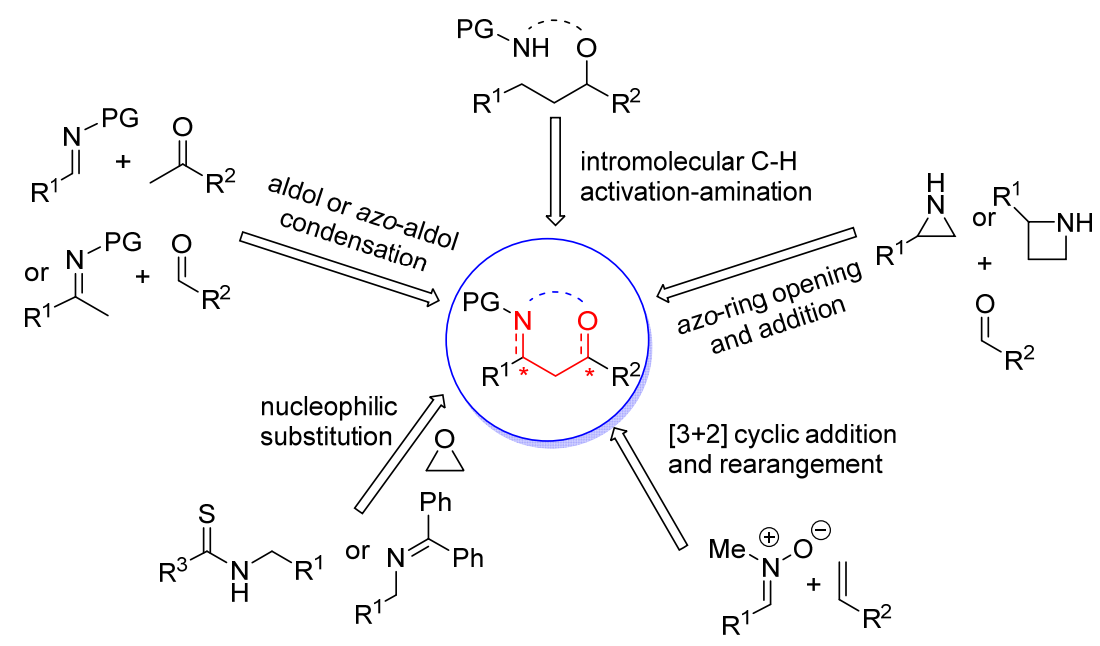

图式 2 1,3-氨基醇类化合物的合成

Scheme 2 Synthesis of 1,3-amino alcohol

则可方便地制备一系列手性 1,3-氨基醇化合物及其衍生 物. 其中, 常用的手性诱导基团有 Enders 手性肼、 Ellman 手性叔丁基亚磺酰酰胺等, 通过取代、加成等反 应可以诱导生成预期手性的产物; 常用的手性有机小分 子催化剂通常基于脯氨酸、喹宁、咪唑啉酮、联䒺酚、 硫脲等, 由于其不含过渡金属、容易制备和修饰、价格 相对低廉、反应条件温和、稳定性好及对环境友好等优 点, 受到众多科学家的青睐, 下面将分别介绍各方法.

\subsection{1 手性辅基诱导制备手性 1,3-氨基醇类化合物}

2000 年, Loh 课题组 ${ }^{[5]}$ 研究了无溶剂条件下, 用 $\mathrm{InCl}_{3}$ 催化烯醇硅醚与手性 $\alpha$-羰基羧酸酯的亲核加成反 应, 得到 $\alpha$-位羰基加成产物, 反应底物中的其它官能团 得以保留. 研究表明, 由于底物的手性诱导, 反应可以 得到 $d e$ 值较高的酯 $\alpha$-位羰基加成产物. 研究还发现, 相 对于位阻更小的苯基, 1 -䒺基位阻更大更有利于烯醇硅 醚加成得 $R$ 型产物(Scheme 3).

2002 年, Ellman 课题组 ${ }^{[6]}$ 首次报道了将手性叔丁基 亚磺酰胺用于诱导不对称加成. 在 Lewis 酸作用下, 手

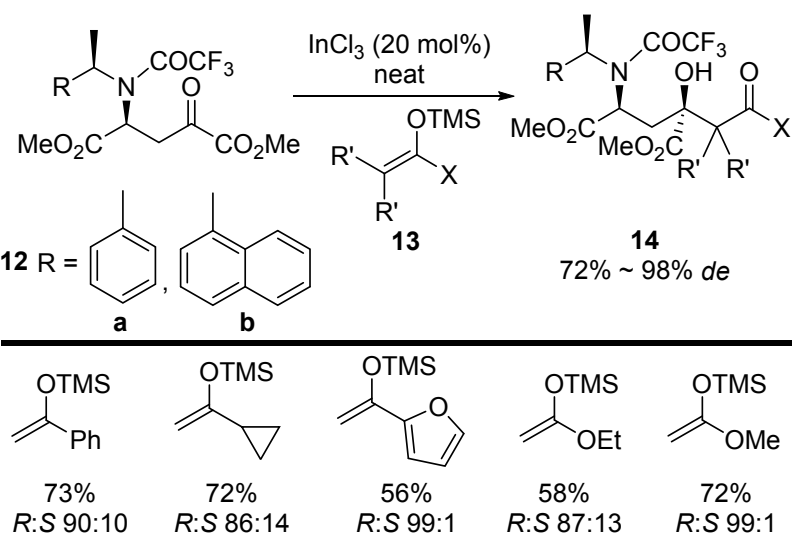

图式 $3 \mathrm{InCl}_{3}$ 催化烯醇硅醚与 $\alpha$-羰基酯的亲核加成反应 Scheme $3 \quad \mathrm{InCl}_{3}$ catalyzed addition of enol ether and $\alpha$-carbonyl ester

性亚磺酰胺与醛/酮加成制得亚磺酰亚胺，一方面在强 碱作用下失去 $\alpha$ 氢, 可作为亲核试剂进攻亲电试剂, 另 一方面亚磺酰亚胺可以接受亲核试剂的进攻, 两种方式 都可以很好地诱导手性目标化合物的制备. 
由手性叔丁基亚磺酰胺与甲基酮衍生的亚胺与醛 aldol 加成反应合成手性的 $\beta$-羟基亚磺酰亚胺, 经过水 解即可得到 $\beta$-羟基酮并回收手性叔丁基亚磺酰胺. 经不 同还原剂的还原可以分别得到 anti 和 syn 式的产物, 如 经过 catecholborane 还原主要得到 $s y n$-1,3-氨基醇, 而经 $\mathrm{LiBHEt}_{3}$ 还原以大于 $99: 1$ 的选择性得到 anti-1,3-氨基 醇(表 1). 随后作者将其应用于生物活性分子 $(-)-8$ Epihalosaline 和(一)-Halosaline 的全合成中(Scheme 4).

表 1 手性叔丁基亚磺酰胺诱导的不对称加成反应

Table 1 Chiral $t$-butylsulfinamide induced asymmetric addition

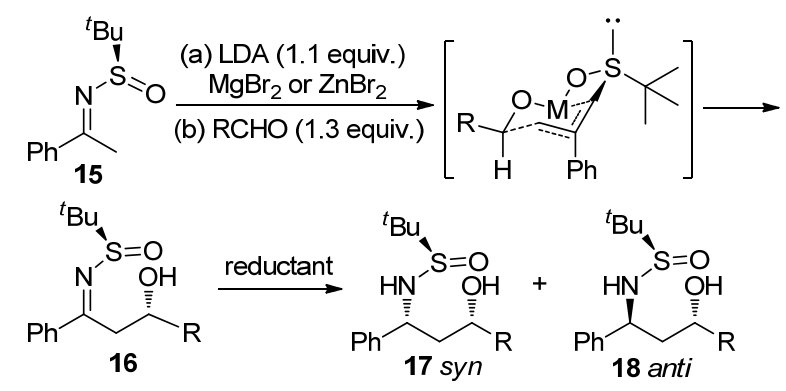

\begin{tabular}{|c|c|c|c|c|}
\hline $\mathrm{R}$ & Reductant & Major isomor & $d r$ & Yield/\% \\
\hline \multirow{2}{*}{ Et } & catecholborane & syn & $95: 5$ & 94 \\
\hline & $\mathrm{LiBHEt}_{3}$ & anti & $>99: 1$ & 69 \\
\hline \multirow{2}{*}{$i-\mathrm{Bu}$} & catecholborane & syn & $96: 4$ & 84 \\
\hline & $\mathrm{LiBHEt}_{3}$ & anti & $>99: 1$ & 85 \\
\hline \multirow{2}{*}{$t-\mathrm{Bu}$} & catecholborane & syn & $96: 4$ & 89 \\
\hline & $\mathrm{LiBHEt}_{3}$ & anti & $>99: 1$ & 91 \\
\hline \multirow{2}{*}{$\mathrm{Ph}$} & catecholborane & syn & $96: 4$ & 84 \\
\hline & $\mathrm{LiBHEt}_{3}$ & anti & $>99: 1$ & 73 \\
\hline
\end{tabular}

${ }_{\mathrm{Bu}^{-}}{ }_{\mathrm{S}}^{\mathrm{O}}{ }_{\mathrm{NH}_{2}}+\mathrm{CH}_{\mathrm{O}}^{\mathrm{O}} \stackrel{\mathrm{Ti}(\mathrm{OEt})_{4}, \mathrm{THF}}{15 \mathrm{~h}}$

(1) LDA, THF, $-78^{\circ} \mathrm{C}$

(2) $\mathrm{MgBr}_{2},-78^{\circ} \mathrm{C}$

(3) butyraldehyde, $-78{ }^{\circ} \mathrm{C}$

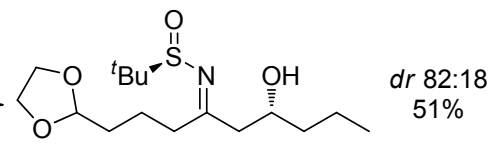

catecholborane, THF

$-48^{\circ} \mathrm{C}, 3 \mathrm{~h}$
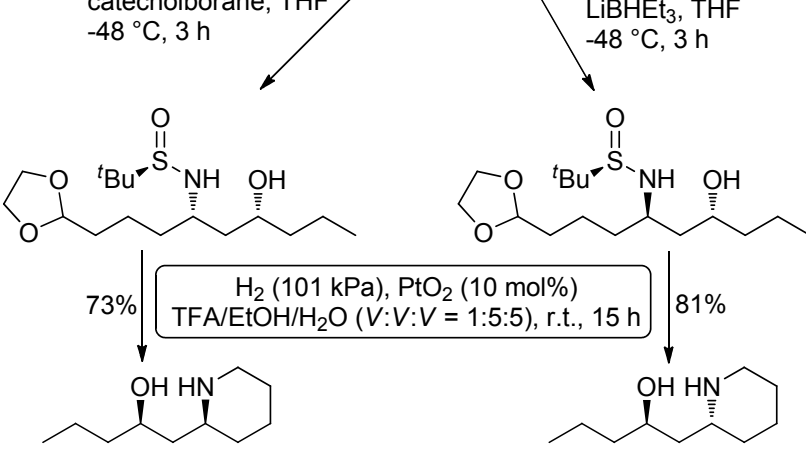

(101 kPa), $\mathrm{PtO}_{2}(10 \mathrm{~mol} \%)$

$\mathrm{OH} / \mathrm{H}_{2} \mathrm{O}(\mathrm{V}: \mathrm{V}: \mathrm{V}=1: 5: 5)$, r.t., $\left.15 \mathrm{~h}\right] 81 \%$

(-)-8-epihalosaline

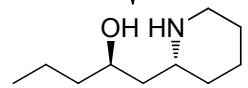

(-)-halosaline

图式 4 (-)-8-Epihalosaline 和(一)-Halosaline 的不对称合成 Scheme 4 Asymmetric synthesis of $(-)$-8-epihalosaline and (一)-halosaline
经研究 ${ }^{[7]}$ 证实, 该方法在 $10 \mathrm{~g}$ 及以上规模的合成反应中 收率稳定、选择性好、纯度高. 自此以后，手性叔丁基 亚磺酰胺 ${ }^{[8]}$ 广泛用于诱导不对称合成 $\beta$-取代醛/酮或胺.

2004 年, Enders 课题组 ${ }^{[9]}$ 利用手性肼与醛或酮缩合 制得一系列的手性腙，在 Lewis 酸 $\mathrm{TiCl}_{4}$ 作用下与醛加成 制得 $\beta$-差基醛腙，经 $\mathrm{TBSCl}$ 保护后再与烃基锂加成，得 到三手性中心的 3-羟基肼，而肼极易还原制备 1,3-氨基 醇. 虽然该方法总体上收率偏低，但选择性非常好(表 2).

表 2 手性腙与醛的加成反应

Table 2 Addition of chiral hydrazine with aldehyde
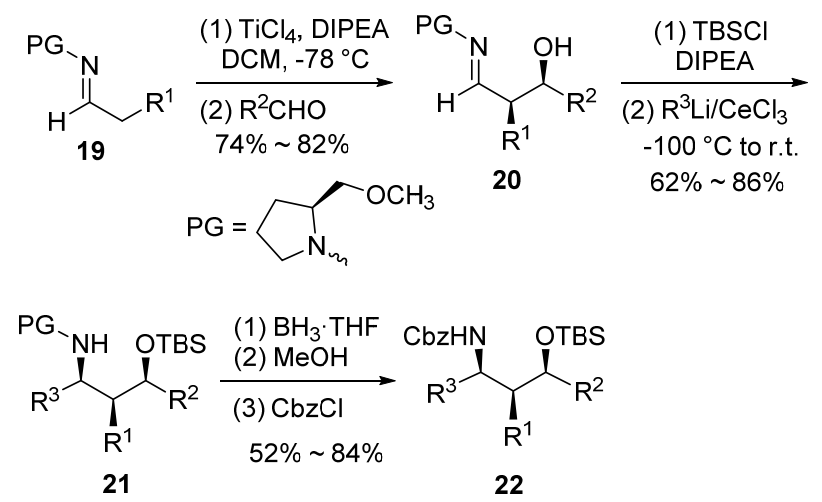

\begin{tabular}{cccccc}
\hline $\mathrm{R}^{1}$ & $\mathrm{R}^{2}$ & $\mathrm{R}^{3}$ & Yield/\% & de/\% & $e e / \%$ \\
\hline $\mathrm{Me}$ & $\mathrm{Ph}$ & $\mathrm{Me}$ & 45 & 96 & 96 \\
$\mathrm{Et}$ & $\mathrm{Ph}$ & $\mathrm{Me}$ & 71 & 83 & 96 \\
$\mathrm{Me}$ & $i-\mathrm{Pr}$ & $\mathrm{Me}$ & 50 & 96 & 96 \\
$\mathrm{Et}$ & $\mathrm{Ph}$ & $n-\mathrm{Bu}$ & 56 & 84 & 96 \\
$\mathrm{Et}$ & $\mathrm{Ph}$ & $\mathrm{Ph}$ & 39 & 78 & 96 \\
\hline
\end{tabular}

1.1 .2 手性脯氨酸及其衍生物催化制备手性 1,3 -氨基 醇类化合物

2000 年, List 课题组 ${ }^{[10]}$ 首次报道了利用有机小分子 $L$-脯氨酸催化的醛、酮与伯胺的三组分串联 Mannich 反 应合成手性 $\beta$-氨基酮的反应，经过简单还原即可方便地 合成 1,3-氨基醇(表 3). 研究发现，在 $35 \mathrm{~mol} \% \mathrm{~L}$-脯氨酸 催化下, 脂肪醛相较芳醛, 反应的收率及 $e e$ 值一般会更 低.

2004 年 Córdova 课题组 ${ }^{[11]}$ 利用芳胺与脂肪醛、芳香 醛反应速率不同及产物稳定性不同的特点，以 $(S)$-脯氨 酸催化三组分(脂肪醛、芳胺、芳醛)Mannich 反应，从而 制备 $\beta$-氨基醛衍生物, 然后经 $\mathrm{NaBH}_{4}$ 还原得 1,3-氨基醇 (表 4). 研究表明, 当芳醛上有吸电子时有利于反应的进 行，同时产物的选择性高，而供电子会导致产率、选择 性都降低.

2005 年, Westermann 课题组 ${ }^{[12]}$ 在研究脯氨酸及其衍 生物催化的酮与亚胺的 Mannich 加成反应构建 $\beta$-氨基酮 的反应中，发现大极性溶剂有利于提高反应的转化率与 
表 $3 \quad L$-脯氨酸催化醛、酮、芳胺三组分反应

Table $3 L$-Proline catalyzed reaction of aldehyde, ketone and aniline

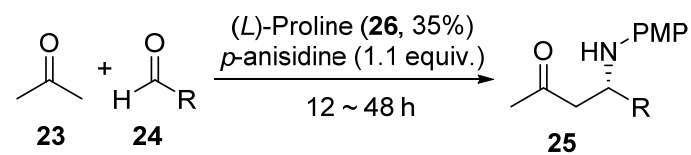

\begin{tabular}{lcl}
\hline \multicolumn{1}{c}{$\mathrm{R}$} & Yield $/ \%$ & $e e / \%$ \\
\hline$p-\mathrm{NO}_{2} \mathrm{C}_{6} \mathrm{H}_{4}$ & 50 & 94 \\
$i-\mathrm{Pr}$ & 56 & 70 \\
$i-\mathrm{Bu}$ & 90 & 93 \\
$n-\mathrm{Bu}$ & 74 & 73 \\
$2-\mathrm{Naphthyl}$ & 35 & 96 \\
$\mathrm{BnOCH}_{2}$ & 82 & 75 \\
\hline
\end{tabular}

表 $4 S$-脯氨酸催化脂肪醛、芳醛、芳胺三组分反应

Table $4 S$-Proline catalyzed reaction of aliphatic aldehyde, aromatic aldehyde and aniline

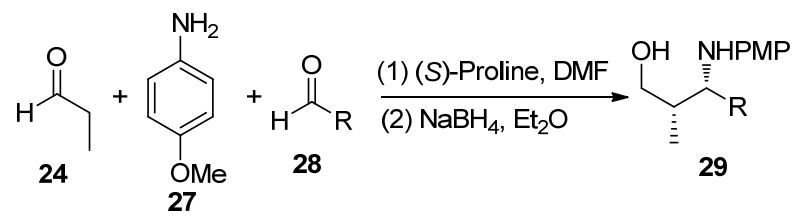

\begin{tabular}{lcccc}
\hline \multicolumn{1}{c}{$\mathrm{R}$} & $T /^{\circ} \mathrm{C}$ & Yield/\% & $d r$ & $e e / \%$ \\
\hline$p-\mathrm{NO}_{2} \mathrm{C}_{6} \mathrm{H}_{4}$ & 4 & 75 & $>19: 1$ & $99^{a}$ \\
$p-\mathrm{NO}_{2} \mathrm{C}_{6} \mathrm{H}_{4}$ & 4 & 41 & $>19: 1$ & $99^{b}$ \\
$\mathrm{Ph}$ & 4 & 62 & $4: 1$ & $75^{a}$ \\
$\mathrm{Ph}$ & 0 & 66 & $>10: 1$ & $88^{b}$ \\
$p-\mathrm{CNC}_{6} \mathrm{H}_{4}$ & 0 & 75 & $>10: 1$ & $98^{a}$ \\
$p-\mathrm{CNC}_{6} \mathrm{H}_{4}$ & -20 & 88 & $>10: 1$ & $99^{b}$ \\
$p-\mathrm{ClC}_{6} \mathrm{H}_{4}$ & -20 & 88 & $>10: 1$ & $99^{b}$ \\
$p-\mathrm{BrC}_{6} \mathrm{H}_{4}$ & -10 & 65 & $>10: 1$ & $99^{b}$ \\
$m-\mathrm{BrC}_{6} \mathrm{H}_{4}$ & -10 & 72 & $>10: 1$ & $99^{b}$ \\
$p-\mathrm{MeOC}_{6} \mathrm{H}_{4}$ & -10 & 50 & $>10: 1$ & $55^{b}$ \\
Furyl & -20 & 80 & $4: 1$ & $84^{b}$ \\
2-Pyridyl & -20 & 86 & $>10: 1$ & $>99^{b}$ \\
2-Pyridyl & -20 & 80 & $>10: 1$ & $>99^{b}$ \\
Cyclohexyl & -20 & trace & N.d. & n.d..$^{b}$ \\
Isopropyl & -20 & trace & N.d. & n.d..$^{b}$ \\
Et & -20 & 82 & $>10: 1$ & $94^{b}$ \\
\hline
\end{tabular}

${ }^{a}(S)$-Proline and arylamine were added at the same time. ${ }^{b}$ Arylamine was added before $(S)$-Proline about $20 \sim 30 \mathrm{~min}$.

及不对称选择性，其中三氟乙醇效果最佳(表 5). 另外, 作者发现亚胺可以由醛与伯胺原位生成, 即可以实现脯 氨酸催化的三组分反应. 值得注意的是, 该反应也可以 通过微波辐射的方式进行.

与 Westermann 课题组的工作类似, Enders 课题组 ${ }^{[13]}$ 用相同(相似)的催化剂实现了醛、伯胺与酮的三组分反 应(表 6). 以丙酮保护的甘油醛为原料则可方便地合成 手性氨基糖. 结果表明, 虽然产率只有中等偏上, 但反 应选择性比较好. 用三仲丁基硼氢化锂将产物 32 的羰
表 5 脯氨酸催化酮与亚胺的加成反应

Table 5 Proline catalyzed addition of ketone and imine

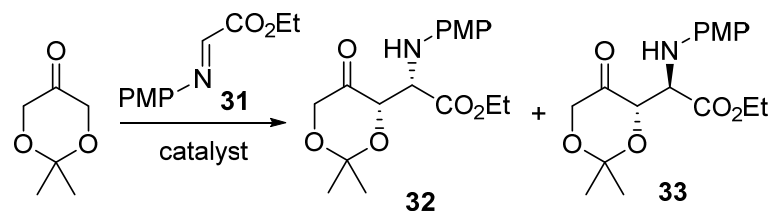

\begin{tabular}{|c|c|c|c|c|c|}
\hline Catalyst & $\begin{array}{c}\text { Conc./ } \\
\mathrm{mol} \%\end{array}$ & Solvent & Yield/\% & $d r$ & $e e / \%$ \\
\hline \multirow{11}{*}{$L$-proline } & 30 & DMSO & 37 & $91: 9$ & 82 \\
\hline & 30 & $\mathrm{H}_{2} \mathrm{O}$ & 34 & $93: 7$ & 34 \\
\hline & 30 & $\mathrm{MeCN}$ & 52 & $93: 7$ & 80 \\
\hline & 30 & $\mathrm{PhMe}$ & 52 & $92: 8$ & 42 \\
\hline & 30 & $\mathrm{BMIMBF}_{4}$ & 39 & $89: 11$ & n.d. \\
\hline & 30 & DMF & 54 & $95: 5$ & 96 \\
\hline & 30 & TFE & 72 & $97: 3$ & 99 \\
\hline & 30 & $\begin{array}{c}\mathrm{TFE} / \mathrm{H}_{2} \mathrm{O}(V: \\
V=95: 5)\end{array}$ & 76 & $95: 5$ & 96 \\
\hline & 20 & TFE & 68 & $96: 4$ & 99 \\
\hline & 10 & TFE & 75 & $95: 5$ & 95 \\
\hline & 5 & TFE & 70 & $93: 7$ & 91 \\
\hline DMTC & 30 & TFE & 28 & $86: 14$ & n.d. \\
\hline
\end{tabular}

基还原以 $98 \%$ 的收率得到保护的氨基糖醇.

2007 年, Fustero 课题组 ${ }^{[14]}$ 也利用脯氨酸衍生物活 化 $\alpha, \beta$-不饱和醛，通过分子内亲核性 $\mathrm{N}$ 对不饱和醛的 1,4-加成构建 $\beta$-氨基醛，而后经过 $\mathrm{NaBH}_{4}$ 还原醛基生成 手性的 1,3-氨基醇(表 7). 不同的底物收率相差较大，但 对映选择性较好; 以格氏试剂为亲核试剂则可制得相应 的手性二级醇. 基于该方法, 可以非常方便地用于合成 哌啶类生物碱 $(+)$-Sedamine 和 $(+)$-Allosedamine (Scheme 5).

2010 年, Kumar 课题组 ${ }^{[15]}$ 采用两步一锅法制备相应 的 1,3-氨基醇(Scheme 6). 作者以叔丁基二甲基硅基 (TBS)保护的手性 $\gamma$-羟基酸为原料, 先经 DIBAL-H 还原 为醛，再经脯氨酸催化与偶氮二甲酸二叔丁酯(DBAD) 加成得手性 2-氨基-4-差基酫中间体，最后经过 HornerWadsworth-Emmons (HWE)反应制备相应的 1,3-氨基醇. 研究发现, $D$-脯氨酸催化得到反式 1,3 -氨基醇, 而 $L$-脯 氨酸催化得到顺式 1,3-氨基醇. 经过雷尼镍催化加氢还 原、TBAF 脱 TBS 制得相应的 1,3-氨基醇,经三步总体收 率为 $67 \%$, 反应具有较高的应用价值.

2010 年, Bäckvall 课题组 ${ }^{[16]}$ 基于 $L$-或 $D$-脯氨酸催化 的酮与亚胺的手性 Mannich 加成反应，将其进一步与 $\mathrm{Ru}$ 催化氢化、动态动力学拆分转化相结合, 可以非常高 效地合成氨基、羟基均被保护的手性 1,3-氨基醇(Scheme 7). 结果表明, 该方法具有非常高的非对映选择性, ee 值均为 $99 \%$. 
表 $6 L$-脯氨酸及其衍生物催化醛、酮、芳胺三组分反应

Table $6 \quad L$-Proline and derivative catalyzed reaction of aldehyde, ketone and aniline<smiles>[Z20]C(C)=O</smiles>

30

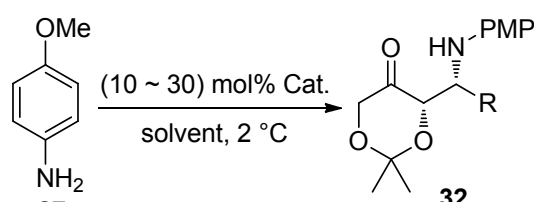
27<smiles>CC(C)(C)OC1CCNC1C(=O)O</smiles>
34<smiles>COC(OC)[C@H](NC(=O)Nc1ccccc1)[C@H]1OC(C)(C)OCC1=O</smiles>
$\geqslant 96 \%$ de, $>99 \%$ ee protected 2-amino-2-deoxy-L-xylose

\begin{tabular}{|c|c|c|c|c|c|c|}
\hline $\mathrm{R}$ & Cat. & Yield/\% & Solvent & $\begin{array}{l}\mathrm{H}_{2} \mathrm{O} / \\
\text { equiv. }\end{array}$ & $d e / \%$ & $e e / \%$ \\
\hline $\mathrm{CH}\left(\mathrm{OCH}_{3}\right)_{2}$ & 26 & 91 & DMF & 4 & $>99$ & 98 \\
\hline $\mathrm{CH}\left(\mathrm{OCH}_{3}\right)_{2}$ & 34 & 98 & DMF & 4 & $>99$ & 93 \\
\hline $\mathrm{CO}_{2} \mathrm{Et}$ & 26 & 91 & DMF & 3 & $\geqslant 96$ & 98 \\
\hline $\mathrm{CO}_{2} \mathrm{Et}$ & 34 & 94 & DMF & - & $\geqslant 96$ & 95 \\
\hline $\mathrm{CH}_{2} \mathrm{OBn}$ & 26 & 94 & NMP & 3 & 60 & 82 \\
\hline \multirow[t]{4}{*}{$\mathrm{CH}_{2} \mathrm{OBn}$} & 34 & 77 & $\mathrm{MeCN}$ & 5 & 88 & 96 \\
\hline & 26 & 57 & DMF & - & 80 & $\geqslant 98$ \\
\hline & 26 & 67 & DMF & - & $\geqslant 96$ & $\geqslant 96$ \\
\hline & 26 & 63 & DMF & - & $\geqslant 96$ & $\geqslant 96$ \\
\hline
\end{tabular}

通过对手性脯氨酸催化原理的深入研究, 人们开发 了一系列类似的小分子催化剂, 如手性咪唑啉酮、手性 硫嫝等.

1.1.3 手性咪唑啉酮催化制备手性 1,3 -氨基醇类化合 物

2006 年, MacMillan 课题组 ${ }^{[17]}$ 报道了以手性咪唑啉 酮为催化剂, 实现差弪胺衍生物对 $\alpha, \beta$-不饱和醛的对映选 择性 1,4-加成反应. 研究发现, 在催化剂 46 的作用下, 以中等的收率得到目标化合物(表 8). 虽然 $\mathrm{N}$ 上的保护 基对收率的影响没有明显规律，但都以非常高的对映选
表 7 脯氨酸衍生物催化分子内胺对 $\alpha, \beta$-不饱和醛 1,4 -加成反 应

Table 7 Proline derivative catalyzed intramolecular 1,4-addition of amine and $\alpha, \beta$-unsaturated aldehyde

$$
\underset{\substack{\mathrm{X}=\mathrm{CH}_{2}, \mathrm{NCbz}, \mathrm{O}, \mathrm{S} \\ n=1,2}}{\text { (b) } \mathrm{NaBH}_{4}, \mathrm{MeOH}} \underset{\substack{\mathrm{Ar} \\ \mathrm{Ar}=3,5-\left(\mathrm{CF}_{3}\right)_{2} \mathrm{C}_{6} \mathrm{H}_{3}}}{\mathrm{Ar}}
$$

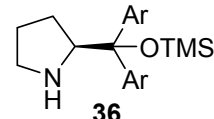

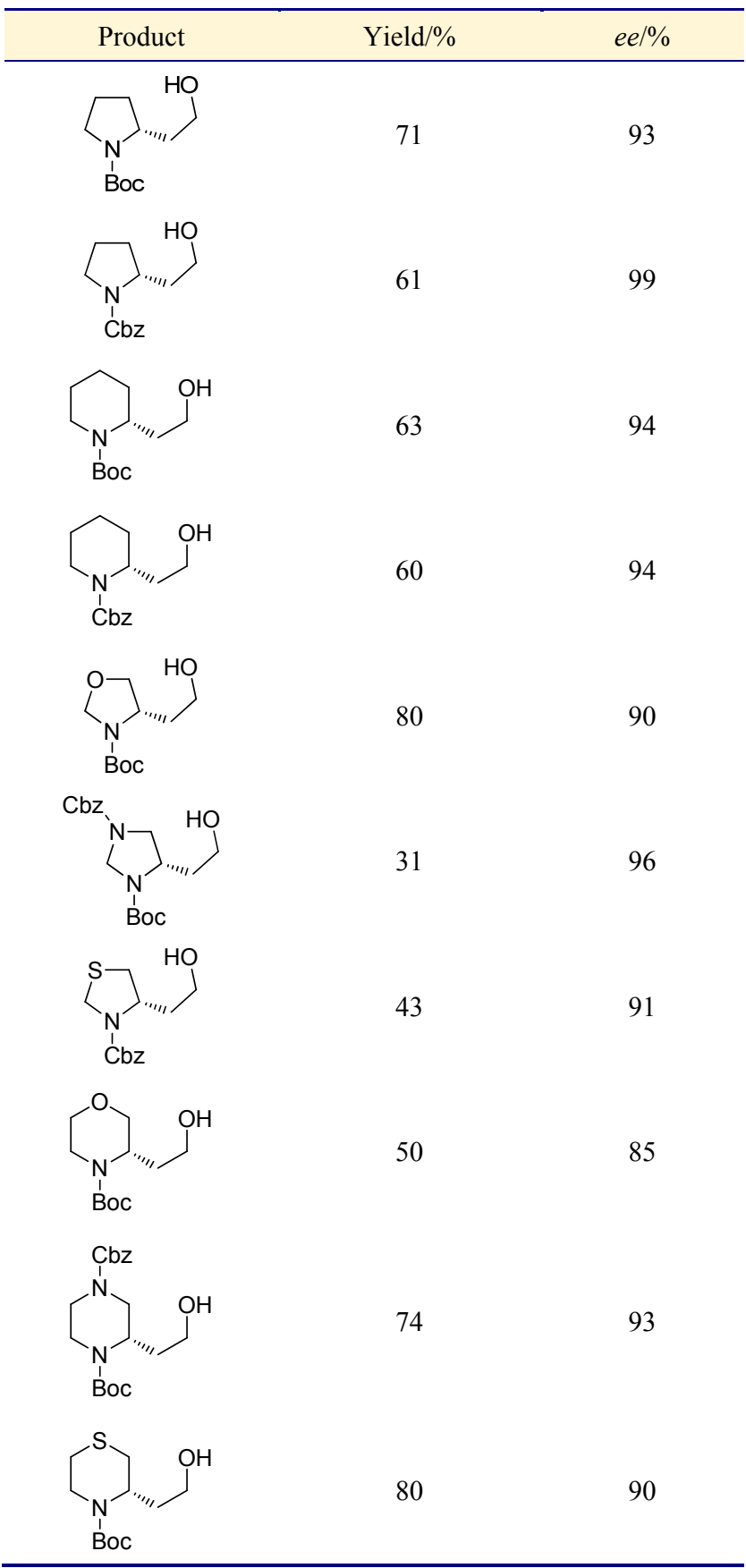




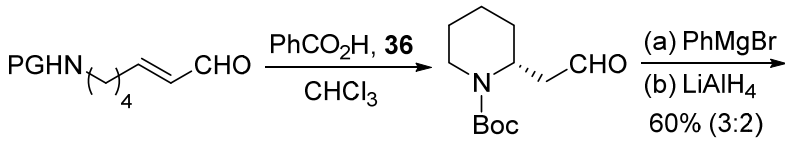

$$
\begin{aligned}
& \overbrace{\substack{N_{1} \\
M e}} \overbrace{\substack{\mathrm{N}_{1} \\
\mathrm{Me}}}^{\mathrm{OH}} \overbrace{\mathrm{Ph}}^{\mathrm{OH}}
\end{aligned}
$$$$
\text { (+)-Sedamine (+)-Allosedamine }
$$

图式 $5(+)$-Sedamine 和 $(+)$-Allosedamine 的不对称合成 Scheme 5 Asymmetric synthesis of (+)-sedamine and (+)allosedamine

择性合成 $\beta$-氨基醛，将羰基还原即可制得 1,3-氨基醇.
研究还发现，生成的 $\beta$-氨基醛经 HWE 反应、分子内 $1,4-$ 加成及 $\mathrm{SmI}_{2}$ 还原, 可以高收率地衍生出 $\beta$-羟基- $\delta$-氨基 羧酸(Scheme 8).

1.1.4 手性硫脲及其衍生物催化制备手性 1,3-氨基醇 类化合物

2002 年, Jacobsen 课题组 ${ }^{[18]}$ 利用手性硫嫝 49 作为催 化剂，以酯衍生烯醇硅醚与 $N$-Boc 亚胺为原料，先经过 加成反应，然后经三氟乙酸脱除 $\mathrm{TBS}$ 基团来构建 $\beta$-氨基 酯衍生物(表 9). 研究表明, 该反应普遍有较高的收率与 较高的 $e e$ 值.
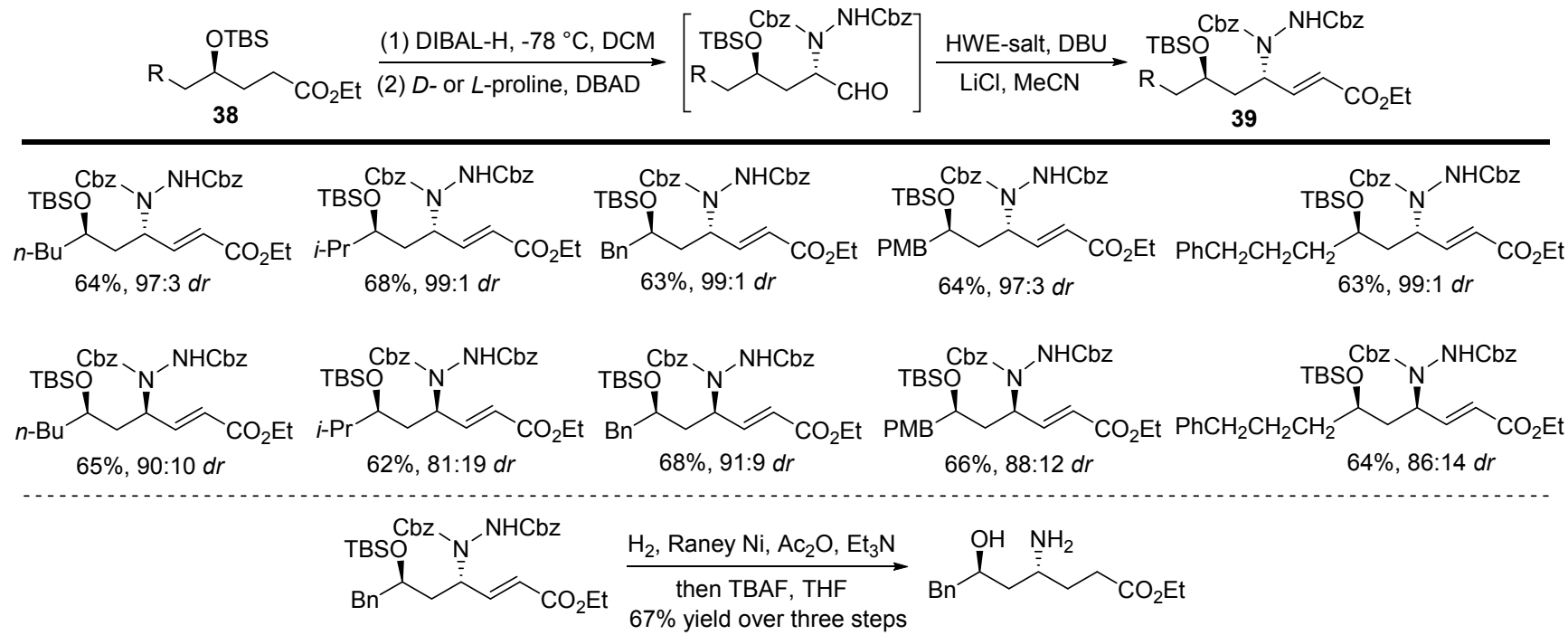

图式 6 脯氨酸催化 4-差基醛与偶氮酯的加成反应

Scheme 6 Proline catalyzed addition of 4-hydroxylaldehyde and DBAD

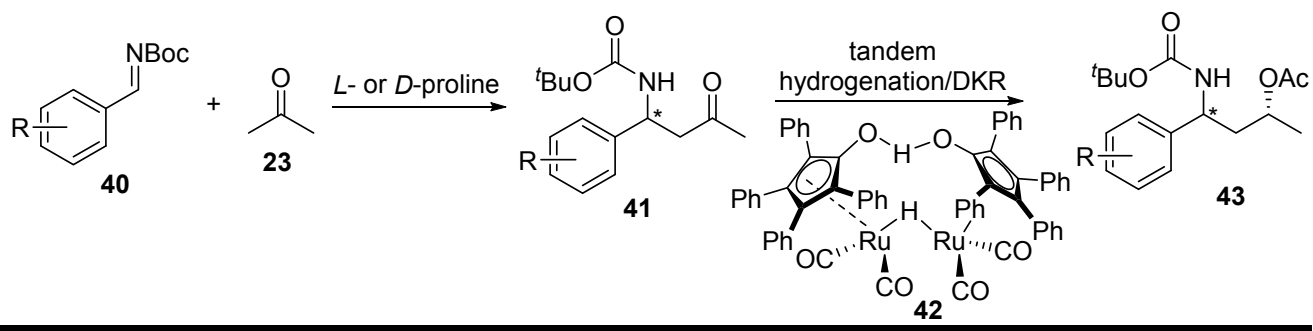

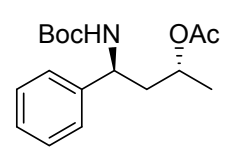

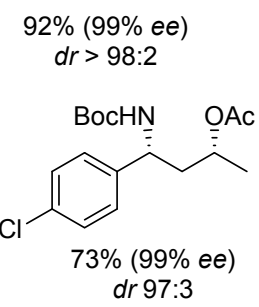

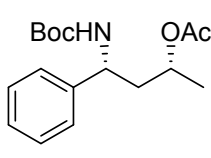

$81 \%(99 \%$ ee $)$ $d r>98: 2$
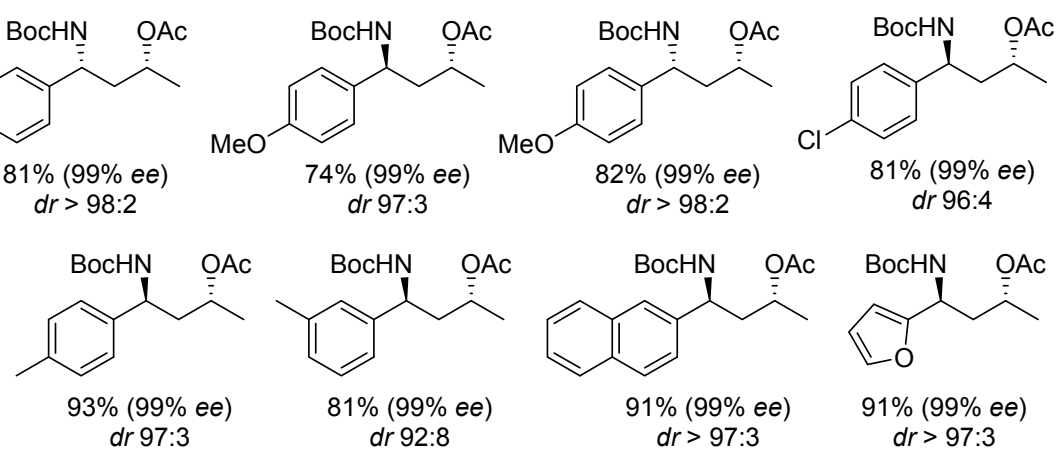

图式 7 手性脯氨酸催化酮与亚胺的加成反应

Sheme 7 Chiral proline catalyzed addition of ketone and imine 
表 8 手性咪唑啉酮催化胺与 $\alpha, \beta$-不饱和醛的 1,4-加成

Table 8 Chiral imidazolidinone catalyzed 1,4-addition of amine and $\alpha, \beta$-unsaturated aldehyde

$$
\overbrace{44}^{\curvearrowright}+{ }_{45}^{P G}
$$

\begin{tabular}{lccc}
\hline \multicolumn{1}{c}{$\mathrm{R}$} & $\mathrm{PG}$ & Yield $/ \%$ & $e e / \%$ \\
\hline $\mathrm{Me}$ & $\mathrm{Cbz}$ & 92 & 92 \\
$n-\mathrm{Pr}$ & $\mathrm{Cbz}$ & 95 & 95 \\
$n-\mathrm{Pr}$ & $\mathrm{Fmoc}$ & 89 & 89 \\
$n-\mathrm{Pr}$ & $\mathrm{Boc}$ & 92 & 92 \\
$\mathrm{PhC}_{2} \mathrm{H}_{4}$ & $\mathrm{Cbz}$ & 69 & 90 \\
$\mathrm{BnOCH}_{2}$ & $\mathrm{Cbc}$ & 70 & 96 \\
$\mathrm{CO}_{2} \mathrm{Me}_{n-\mathrm{Pr}}$ & $\mathrm{Boc}$ & 78 & 97 \\
& $\mathrm{Boc}$ & 85 & 92 \\
& & & \\
& $\mathrm{Cbz}$ & 87 & 96
\end{tabular}

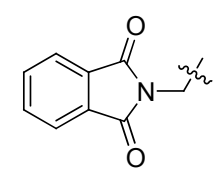

Boc

85

87
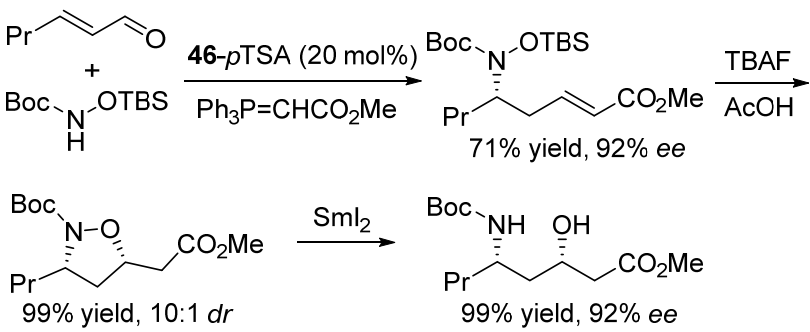

图式 $8 \beta$-差基- $\delta$-氨基羧酸的合成

Scheme 8 Synthesis of $\beta$-hydroxyl- $\delta$-amino acid

2017 年, Alemán 课题组 ${ }^{[19]}$ 利用手性硫脲-喹宁催化 烯醇硅醚与亚胺的氮杂 Baylis-Hillman 反应合成 2-氨基 醛(表 10). 该反应条件温和, 具有非常高的对映选择性. 研究发现, 芳醛亚胺产率较高, 而脂肪醛亚胺收率偏低. 此外, $\mathrm{Ar}^{2}$ 基团为苯并噻唑或苯并噁唑时有利于反应的 进行, 但 $\mathrm{Ar}^{2}$ 为 $\mathrm{Ts}$ 时对映选择性只有 $50 \%$, 该反应得到 的产物可以非常方便地进行转化.

\subsection{5 路易斯酸催化制备手性 1,3-氨基醇类化合物}

除了手性有机小分子, 路易斯酸类催化剂也常常用 于催化 1,3-氨基醇类化合物的合成.

2004 年, Hoveyda 课题组 ${ }^{[20]}$ 报道了醋酸银与手性膦 配体催化的烯醇硅醚与亚胺的 Mannich 加成反应(表 11). 研究表明, 该反应催化效率较高, 催化剂用量为 $(1 \sim 5)$
表 9 手性硫嫝催化 $N$-Boc 亚胺与烯醇硅醚的加成反应 Table 9 Chiral thiourea catalyzed addition of $N$-Boc imine and silyl enol ether

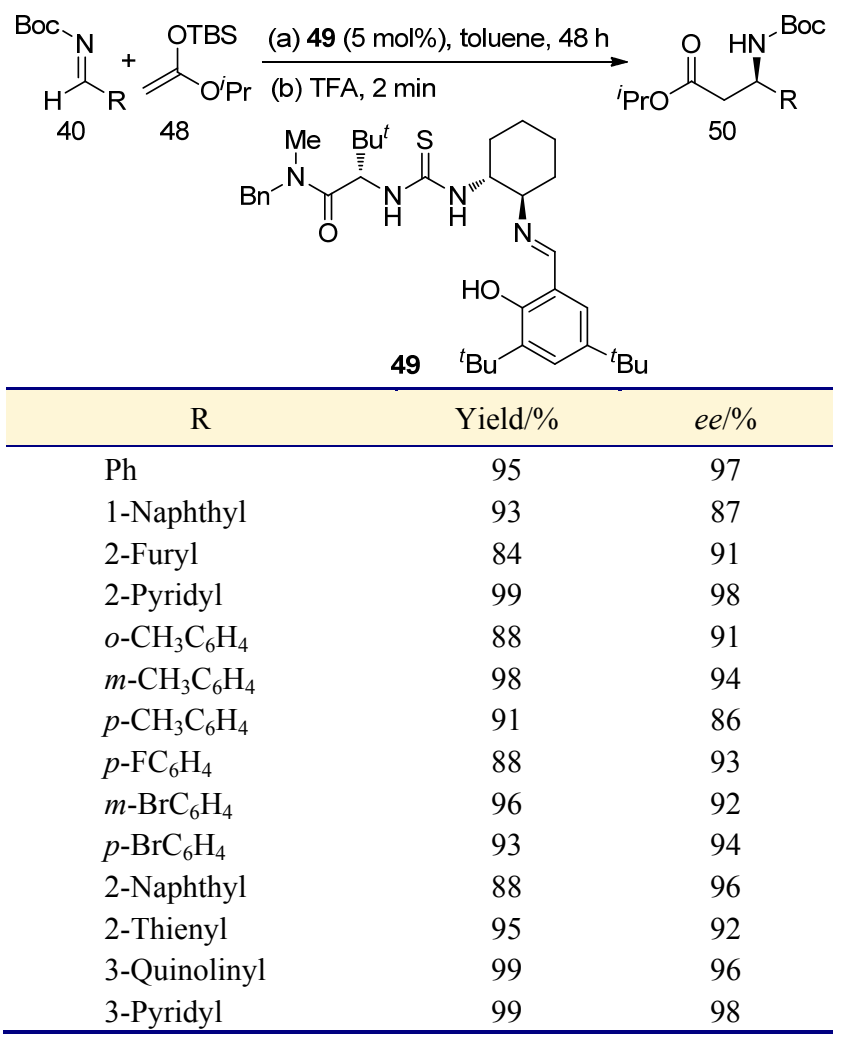

$\mathrm{mol} \%$, 并且反应条件非常温和, 不需要无水无氧条件, 室温下即可进行。同时，该反应选择性普遍较好，其中 富电子芳醛亚胺产率相对较低, 而缺电子芳醛亚胺产率 则相对较高. 该催化体系也可以应用于醛、芳胺与烯醇 硅醚三组分串联反应，实现手性 $\beta$-氨基酮的构建，其产 率和选择性并未受到显著影响. 作者将其应用到天然产 物(一)-Sedamine 的对映选择性全合成中，经过加成、分 子内成酰胺及羰基还原，目标化合物的总产率可达 $40 \%$ (Scheme 9).
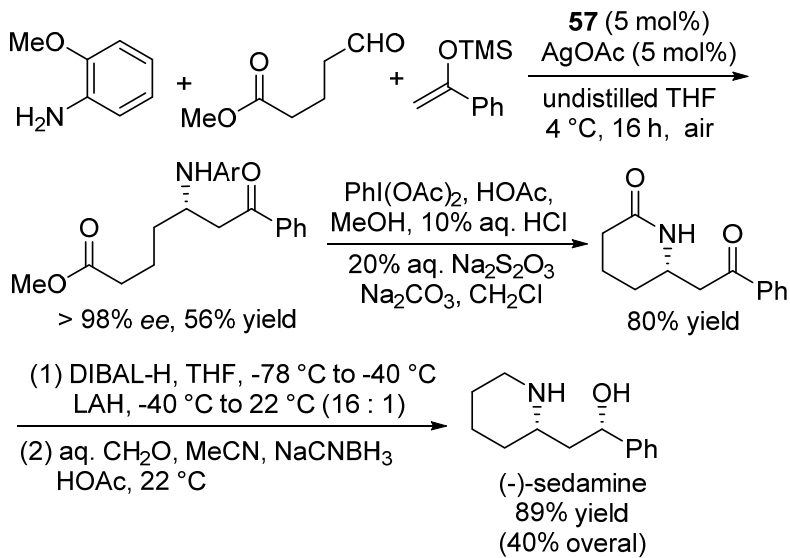

图式 9 (一)-Sedamine 的不对称合成

Scheme 9 Asymmetric synthesis of $(-)$-sedamine 
表 10 手性硫脲一喹宁催化 $\alpha, \beta$-不饱和烯醇硅醚与亚胺的氮杂 $\mathrm{BH}$ 反应

Table 10 Chiral thiourea-quinine catalyzed Baylis-Hillman addition of $\alpha, \beta$-unsaturated silyl enol ether and imine

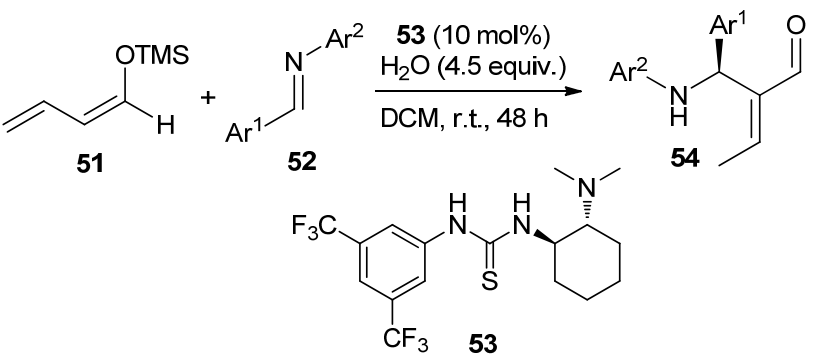

\begin{tabular}{|c|c|c|c|}
\hline $\mathrm{Ar}^{1}$ & $\mathrm{Ar}^{2}$ & Yield/\% & $e e / \%$ \\
\hline $\mathrm{Ph}$ & & 84 & $>99$ \\
\hline 4- $\mathrm{MeC}_{6} \mathrm{H}_{4}$ & & 87 & $>99$ \\
\hline $4-\mathrm{MeOC}_{6} \mathrm{H}_{4}$ & & 80 & $>99$ \\
\hline $4-\mathrm{CF}_{3} \mathrm{C}_{6} \mathrm{H}_{4}$ & & 75 & $>99$ \\
\hline 2-Thienyl & & 78 & 99 \\
\hline 2-Furyl & & 82 & 95 \\
\hline 4- $\mathrm{BrC}_{6} \mathrm{H}_{4}$ & & 86 & $>99$ \\
\hline $2-\mathrm{MeC}_{6} \mathrm{H}_{4}$ & & 81 & 99 \\
\hline 1-Naphthyl & & 83 & 93 \\
\hline Styryl & & 75 & 93 \\
\hline \multirow[t]{3}{*}{$\mathrm{Cy}$} & & 62 & 86 \\
\hline & & 73 & 87 \\
\hline & & 80 & $>99$ \\
\hline & & 83 & $>99$ \\
\hline & & 85 & $>99$ \\
\hline $\mathrm{Ph}$ & Ts & 90 & 50 \\
\hline
\end{tabular}

2004 年, Shibasaki 课题组 ${ }^{[21]}$ 以 $\mathrm{Et}_{2} \mathrm{Zn}$ 与 $(S, S)$-linkedBINOL 生成的路易斯酸联菜酚锌试剂作为催化剂, 以 $\alpha$-羟基酮与亚胺为原料, 通过非对映选择性 Mannich 加 成反应来合成 1,3-氨基醇类化合物(表 12). 研究表明, 该体系的普适性好, 产物的对映选择性非常高, ee 值高 达 99\%. 在 1 5 mol\%的催化剂用量下绝大部分底物都 可以实现非常高的转化率, 只有个别底物转化率小于 $90 \%$. 而通过改变亚胺 $N$ 上的取代基和反应温度可以选 择性生成 anti 和 $s y n$ 产物：当 $\mathrm{PG}$ 为二苯膦氧基 $\left[\mathrm{P}(\mathrm{O}) \mathrm{Ph}_{2}\right]$ 时, 主要产物为 anti 型; 而 PG 为叔丁氧羰基(Boc)时, 主要产物为 $s y n$ 型.

2018 年, Trost 课题组 ${ }^{[22]}$ 采用手性锌催化二取代乙 醛与亚胺加成反应来构建 2-氨基醛化合物(Scheme 10), 该反应可以方便地构建手性季碳. 研究表明, 乙醛上的
表 11 银( $\mathrm{I})$ 手性膦配体催化亚胺与烯醇硅醚的加成反应 Table $11 \mathrm{Ag} /$ chiral phosphine catalyzed addition of imine and silyl enol ether

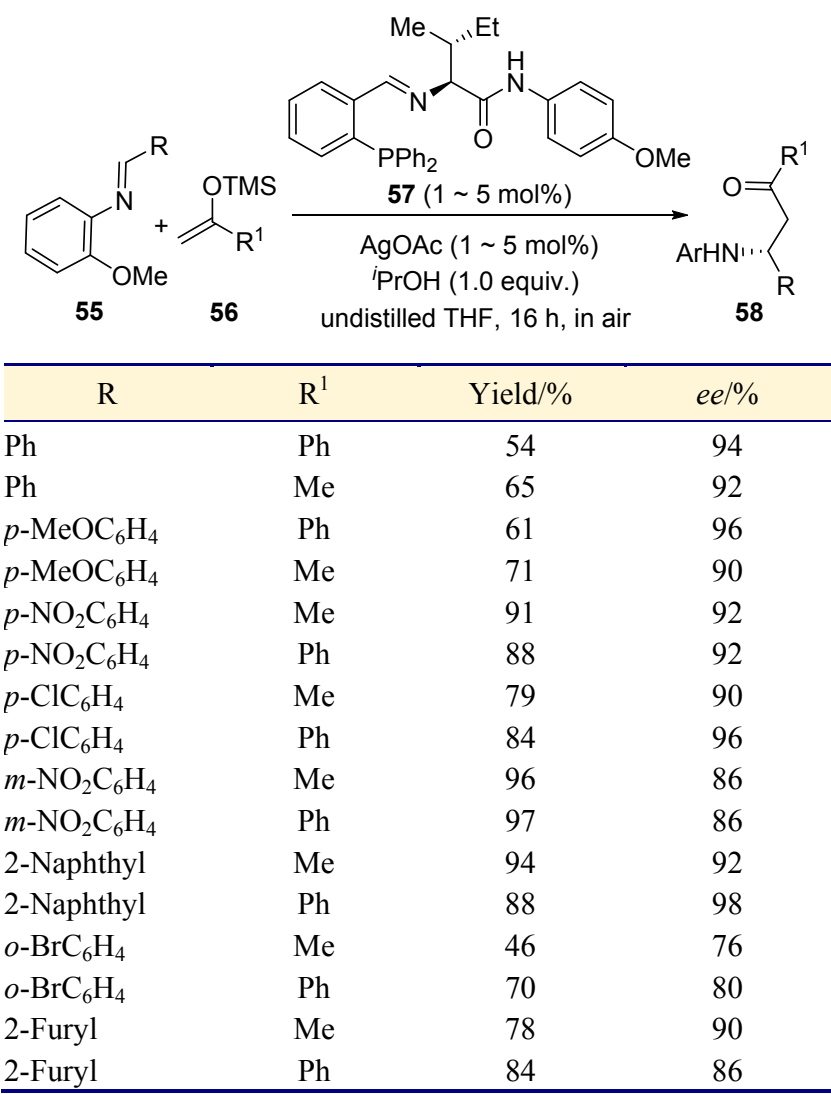

表 $12 \mathrm{Zn}(\mathrm{II}) /$ 联菜酚催化 $\alpha$-羟基芳乙酮与亚胺的加成反应 Table $12 \mathrm{Zn}$ II $/$ binaphthol catalyzed addition of $\alpha$-hydroxyacetophenone

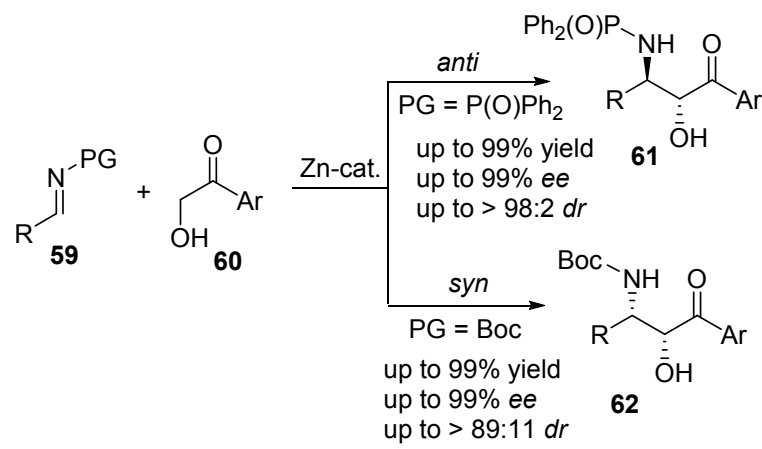

\begin{tabular}{clcccc}
\hline $\mathrm{PG}$ & \multicolumn{1}{c}{$\mathrm{R}$} & Product & Yield/\% & $d r$ (anti/syn $)$ & $e$ ee $\%$ \\
\hline \multirow{6}{*}{$\mathrm{P}(\mathrm{O}) \mathrm{Ph}_{2}$} & 4- $\mathrm{MeC}_{6} \mathrm{H}_{4}$ & anti & 98 & $96 / 4$ & 98 \\
& 4- $\mathrm{MeOC}_{6} \mathrm{H}_{4}$ & anti & 98 & $96 / 4$ & 99 \\
& 1-Naphthyl & anti & 97 & $95 / 5$ & 99 \\
& 2-Furyl & anti & 98 & $98 / 2$ & $>99.5$ \\
\hline \multirow{6}{*}{$\mathrm{Boc}$} & $\mathrm{Ph}$ & syn & 94 & $88 / 12$ & 99 \\
& 4- $\mathrm{MeOC}_{6} \mathrm{H}_{4}$ & syn & $>99$ & $85 / 15$ & 99 \\
& 1-Naphthyl & syn & 85 & $95 / 5$ & 99 \\
& 2-Furyl & syn & $>99$ & $82 / 18$ & $>99.5$ \\
& 2-Thienyl & syn & $>99$ & $86 / 14$ & 99 \\
\hline
\end{tabular}




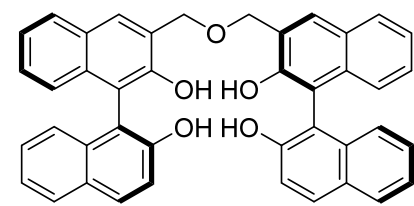

$(S, S)$-linked-BINOL

两个取代基位阻大的会严重影响反应的产率和选择性. 该催化剂还可用于后续催化亲核试剂(如甲基酮)对醛的 加成, 选择性非常好, $d r$ 值普遍大于 $10 ： 1$.

\section{2 过渡金属催化 $\mathrm{C}-\mathrm{H}$ 键活化、氨化反应}

自上世纪六七十年代以来, 过渡金属催化在有机合 成反应方面一直倍受有机化学家的关注. 通过过渡金属 催化的 $\mathrm{C}-\mathrm{H}$ 活化、氨化是另一类构造 1,3-氨基醇非常 重要的合成手段, 也是近些年研究的热点.

\subsection{1 铑催化 1,3-氨基醇类化合物的合成}

2001 年, Bois 课题组 ${ }^{[23]}$ 报道了一例以氨基磺酸酯为 原料, 醋酸铑 $\left[\mathrm{Rh}_{2}(\mathrm{OAc})_{4}\right]$ 为催化剂、醋酸碘苯 $[\mathrm{PhI}-$ $(\mathrm{OAc})_{2}$ ]为氧化剂的分子内 $\gamma-\mathrm{C}-\mathrm{H}$ 活化反应, 从而实现 1,3-氨基醇的合成的方法(Scheme 11). 该反应产率中等
偏上，产物以顺式为主，选择性大于 $8 ： 1$. 基于此方法, 经 $\mathrm{CBzCl}$ 保护、 $\mathrm{NaOCl} / \mathrm{NaClO}_{2}$ 氧化可以方便地制备手 性 $\beta$-氨基酸. 随后作者采用分步氧化、烯丙基硅醚加成 ${ }^{[24]}$ 的方式提高了反应的非对映选择性. 2017 年, Schomaker 课题组 ${ }^{[25]}$ 采用类似的策略, 即分步氧化、格氏试 剂加成的方式制得叔碳氨基醇，以顺式产物为主，但反 应的选择性得到显著提高, 其非对映选择性大于 $19: 1$.

2008 年, Bois 课题组 ${ }^{[26]}$ 通过修饰 Rh 所接的配体实 现了苄位、烯丙位不对称 $\mathrm{C}$ - $\mathrm{H}$ 活化、氨化(Scheme 12). 在茮位氨化反应中, 富电子底物活性较高, 选择性也相 对更好, 而缺电子底物产率降低较显著; 在烯丙位不对 称 $\mathrm{C}-\mathrm{H}$ 氨化反应中存在副产物 $\mathrm{N}$ 杂环丙烷的生成, 采 用 $S$-nap 配体可以大大减少该副产物的生成，但总体上 产率浮动较大，但 $e e$ 值中等偏上(表 13).

2016 年, Breit 课题组 ${ }^{[27]}$ 采用 $[\mathrm{Rh}(\mathrm{cod}) \mathrm{Cl}]_{2}$ 催化联烯 分子内氨化制备噁嗪酮(表 14). 通过调节添加剂可以调 节产物的顺/反结构: $\mathrm{PhMe}_{2} \mathrm{CCO}_{2} \mathrm{H}$ 利于反式产物的生 成, 而 $\mathrm{LiCl} / \mathrm{PPTS}$ 有利于顺式产物的生成. 研究发现, R
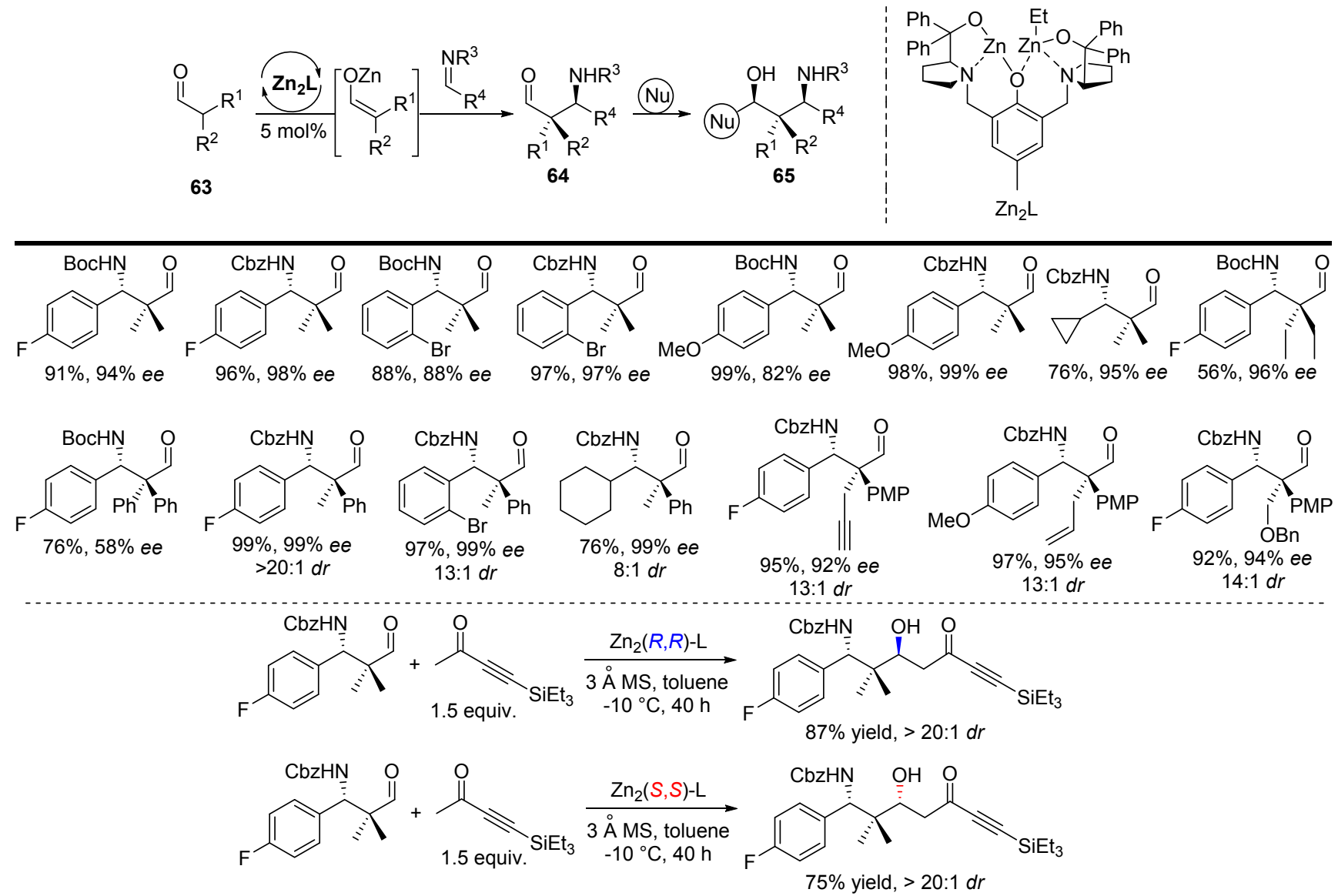

图式 10 手性锌催化醛与亚胺的加成反应

Scheme 10 Chiral Zn(II) catalyzed addition of aldehyde and imine 

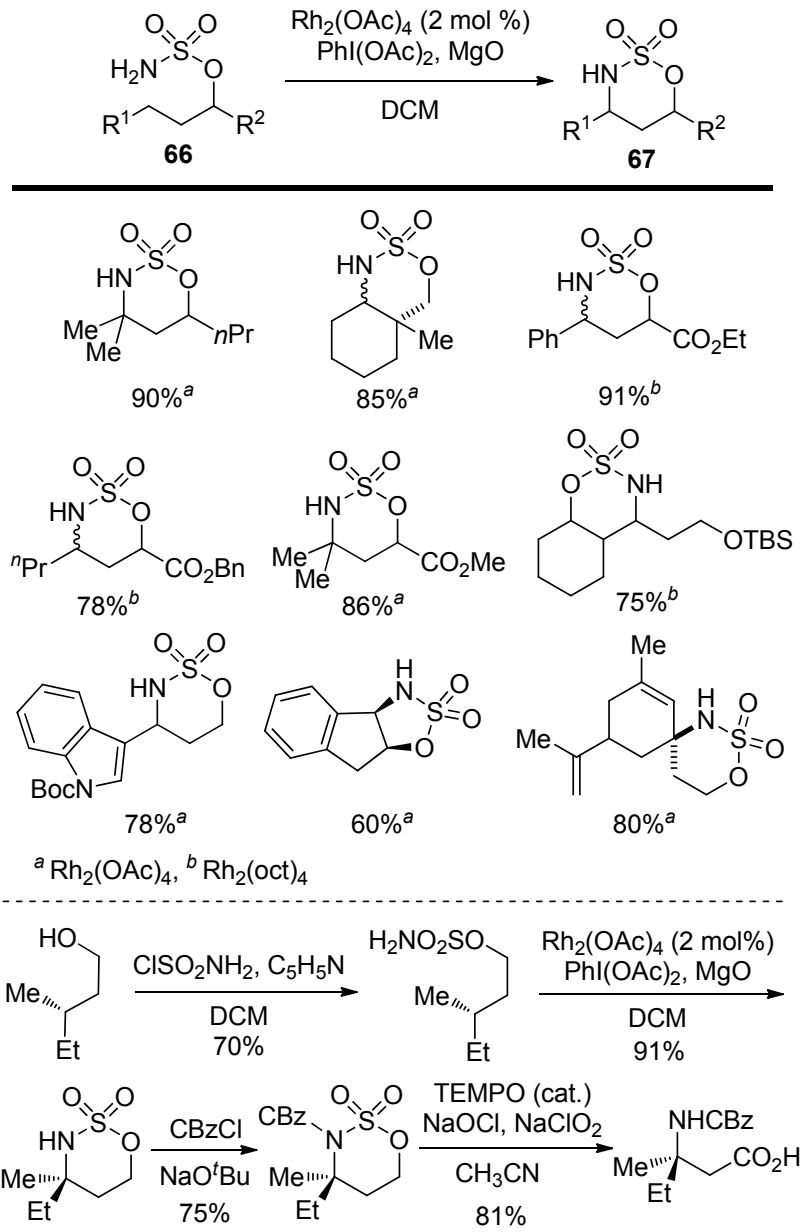

图式 11 铑催化氨基磺酸酯分子内 $\mathrm{C}-\mathrm{H}$ 活化、氨化反应

Scheme $11 \mathrm{Rh}(\mathrm{OAc})_{2}$ catalyzed intramolecular $\mathrm{C}-\mathrm{H}$ activation and amination of sulfamate

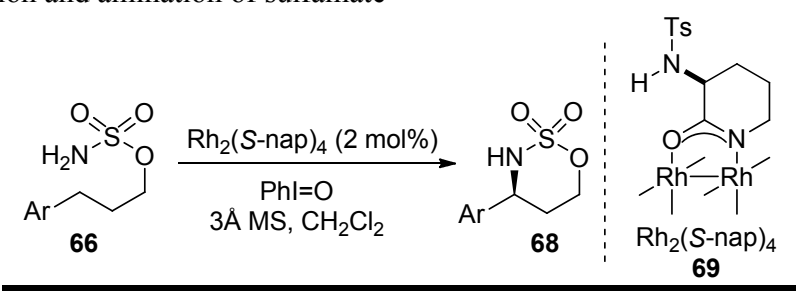

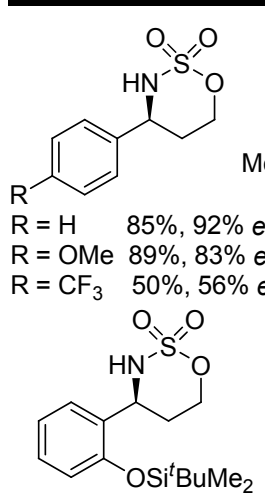

$45 \%, 85 \%$ ee

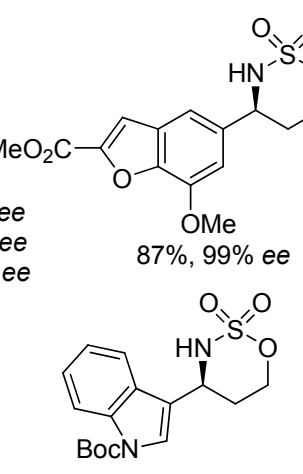

$98 \%, 92 \%$ ee

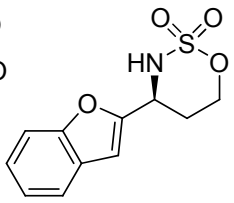

$72 \%, 63 \%$ ee

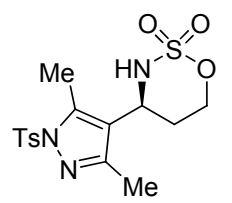

$55 \%, 94 \%$ ee
图式 12 铑催化氨基磺酸酯分子内苠位 $\mathrm{C}-\mathrm{H}$ 活化、氨化反 应

Scheme $12 \mathrm{Rh}_{2}(S \text {-nap })_{4}$ catalyzed intramolecular benzyl C-H activation and amination of sulfamate
表 13 铑催化氨基磺酸酯分子内烯丙位 $\mathrm{C}-\mathrm{H}$ 活化、氨化反 应

Table $13 \mathrm{Rh}_{2}(S \text {-nap })_{4}$ catalyzed intramolecular allylic $\mathrm{C}-\mathrm{H}$ activation and amination of sulfamate

\begin{tabular}{|c|c|c|c|c|}
\hline $\mathrm{R}$ & Catalyst & Ratio $68 / 70$ & Yield/\% & $e e / \%$ \\
\hline \multirow{3}{*}{$\mathrm{Ph}$} & $\mathrm{Rh}_{2}(\mathrm{OAc})_{4}$ & $1: 20$ & & \\
\hline & $\mathrm{Rh}_{2}(\mathrm{PTPI})_{4}$ & $1: 3$ & & \\
\hline & $\mathrm{Rh}_{2}(S \text {-nap })_{4}$ & $2: 1$ & 48 & 12 \\
\hline \multirow{2}{*}{$\mathrm{H}$} & $\mathrm{Rh}_{2}(\mathrm{OAc})_{4}$ & $1: 1$ & & \\
\hline & $\mathrm{Rh}_{2}(S \text {-nap })_{4}$ & $>20: 1$ & 43 & 13 \\
\hline \multirow{2}{*}{$\mathrm{Me}$} & $\mathrm{Rh}_{2}(\mathrm{OAc})_{4}$ & $2: 1$ & & \\
\hline & $\mathrm{Rh}_{2}(S \text {-nap })_{4}$ & $>20: 1$ & 51 & 54 \\
\hline \multirow{2}{*}{$\operatorname{Me}(Z)$} & $\mathrm{Rh}_{2}(\mathrm{OAc})_{4}$ & $1: 1$ & & \\
\hline & $\mathrm{Rh}_{2}(S \text {-nap })_{4}$ & $>20: 1$ & 48 & 82 \\
\hline \multirow{2}{*}{$\mathrm{Ph}(Z)$} & $\mathrm{Rh}_{2}(\mathrm{OAc})_{4}$ & $2: 1$ & & \\
\hline & $\mathrm{Rh}_{2}(S \text {-nap })_{4}$ & $>20: 1$ & 55 & 84 \\
\hline
\end{tabular}

表 14 铑催化联烯分子内氨化反应

Table $14[\mathrm{Rh}(\operatorname{cod}) \mathrm{Cl}]_{2}$ catalyzed amination of allene

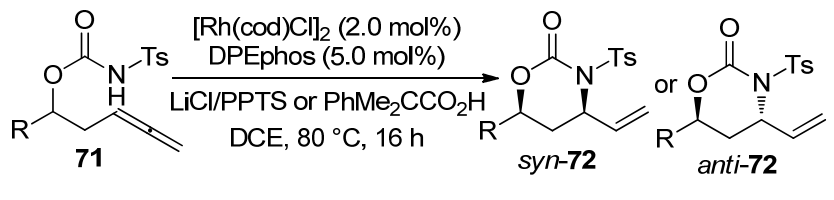

\begin{tabular}{lccccc}
\hline \multirow{2}{*}{$\mathrm{R}$} & \multicolumn{3}{c}{ syn } & \multicolumn{3}{c}{ anti } \\
\cline { 2 - 3 } \cline { 5 - 6 } & Yield/\% & $d r$ & & Yield/\% & $d r$ \\
\hline $\mathrm{Ph}$ & 81 & $91: 9$ & & 98 & $89: 11$ \\
2-Naththyl & 76 & $90: 10$ & & 97 & $92: 8$ \\
4- $\mathrm{PhC}_{6} \mathrm{H}_{4}$ & 96 & $91: 9$ & & 96 & $89: 11$ \\
$4-\mathrm{MeC}_{6} \mathrm{H}_{4}$ & 80 & $92: 8$ & & 92 & $90: 10$ \\
$3-\mathrm{MeC}_{6} \mathrm{H}_{4}$ & 70 & $91: 9$ & & 98 & $85: 15$ \\
$2-\mathrm{MeC}_{6} \mathrm{H}_{4}$ & 84 & $89: 11$ & 98 & $86: 14$ \\
$4-\mathrm{MeOC}_{6} \mathrm{H}_{4}$ & 74 & $91: 9$ & 94 & $88: 12$ \\
$4-\mathrm{MeSC}_{6} \mathrm{H}_{4}$ & 88 & $95: 5$ & 97 & $88: 12$ \\
$4-\mathrm{BrC}_{6} \mathrm{H}_{4}$ & 74 & $90: 10$ & 88 & $53: 47$ \\
$4-\mathrm{CF}_{3} \mathrm{C}_{6} \mathrm{H}_{4}$ & 88 & $90: 10$ & & 92 & $83: 17$ \\
${ }^{i} \mathrm{PrO}_{2} \mathrm{CCH}_{2}$ & 96 & $87: 13$ & & 99 & $90: 10$ \\
${ }^{i} \mathrm{Pr}$ & 91 & $88: 12$ & & 96 & $78: 22$ \\
$\mathrm{Cyclopropyl}$ & 63 & $87: 13$ & & 94 & $78: 22$ \\
$\mathrm{TBSOCH}_{2} \mathrm{CH}_{2}$ & 95 & $87: 13$ & & 98 & $88: 12$ \\
$\mathrm{C}_{8} \mathrm{H}_{17}$ & 96 & $87: 13$ & 98 & $88: 12$ \\
\hline
\end{tabular}

基团为芳基时产率比脂肪基略好，选择性也更高; 此外， 相同的底物，反式产物的收率比顺式产物高，但选择性 比顺式产物稍差.

\subsection{2 钯催化 1,3-氨基醇类化合物的合成}

2009 年, White 课题组 ${ }^{[28]}$ 采用二亚砜作配体, 研究 了 $\mathrm{Pd}(\mathrm{OAc})_{2}$ 催化分子内烯丙位氨化反应构建噁嗪酮的 方法(Scheme 13). 作者研究了底物 $\mathrm{N}$ 上取代基对反应的 
影响，如 $p$ - Tol、 $p-\mathrm{ClC}_{6} \mathrm{H}_{4} 、 p-\mathrm{NO}_{2} \mathrm{C}_{6} \mathrm{H}_{4}(\mathrm{Ns}) 、 o-\mathrm{NO}_{2} \mathrm{C}_{6} \mathrm{H}_{4}$ 等, 发现 Ns 作为取代基时产率最高, 选择性最好, 且产 物以顺式为主. 底物研究中可以看出, 产物只有中等收 率. 作者以手性底物为原料将该方法用于 $(+)$-allosedridine 的全合成中, 六步总收率 $27 \%$, 产物 ee 值大于 $99 \%$.

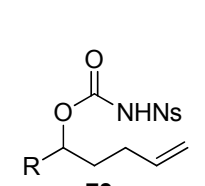

73

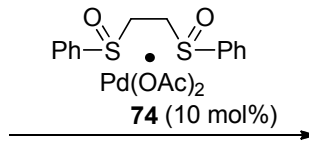

$\mathrm{PhBQ}$ (2 eqiuv.) DCE $(0.66 \mathrm{~mol} / \mathrm{L}), 45^{\circ} \mathrm{C}, 24 \mathrm{~h}$

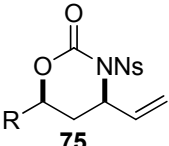

75<smiles>C=CC1CCOC(=O)N1</smiles>

$70 \%$

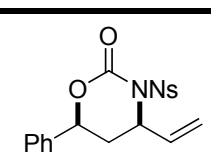

$83 \%, 6.8: 1 d r$ $(64 \%,>20: 1 d r)^{a}$

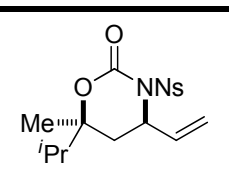

$82 \%, 2.5: 1 d r$ $(51 \%,>20: 1 d r)^{a}$<smiles>C=CC1CC(COCc2ccccc2)OC(=O)N1S(=O)(=O)[O-]</smiles><smiles>C=CC1CC(CC/C=C/C#N)OC(=O)N1S(=O)(=O)[O-]</smiles>

${ }^{a}$ Isolated yield of major syn product, > 20:1 syn:anti

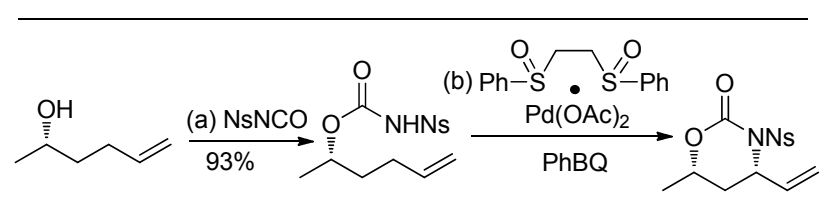

(e) Grubbs(II)

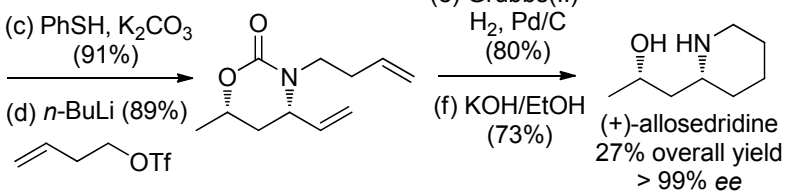

图式 13 钯催化碳酸酷酰胺分子内烯丙位 $\mathrm{C}-\mathrm{H}$ 活化、氨化 反应

Scheme $13 \mathrm{Pd}(\mathrm{OAc})_{2}$ catalyzed intramolecularly allyl $\mathrm{C}-\mathrm{H}$ activation and amination of carbonate amide

2010 年, White 课题组 ${ }^{[29]}$ 研究了不同路易斯酸作为 添加剂对烯丙位 $\mathrm{C}-\mathrm{H}$ 键活化-胺化用于构建含 $\beta$-内酰 胺基团的 syn-噁嗪酮反应的影响(表 15). 研究发现, 在 构建五元环时 $\mathrm{Cr}$ (salen) $\mathrm{Cl}$ 的加入仅能略微提高收率, 而 在六元环的构建中影响较为显著; 另外添加剂对反应速 率的提升非常明显. 此外, 该反应还能实现分子间的反 应.
表 15 路易斯酸对钯催化碳酸酯酰胺分子内烯丙位 $\mathrm{C}-\mathrm{H}$ 活 化、氨化的影响

Table 15 The influence of Lewis acid on the $\operatorname{Pd}(\mathrm{OAc})_{2}$ catalyzed intramolecularly allyl $\mathrm{C}-\mathrm{H}$ activation and amination of carbonate amide

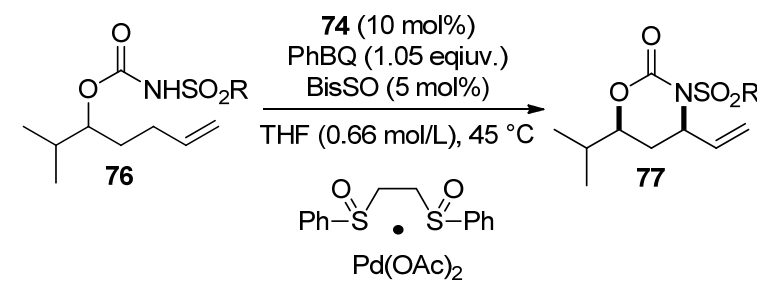

74

\begin{tabular}{lcccc}
\hline \multicolumn{1}{c}{$\mathrm{R}$} & Additive & Time $/ \mathrm{h}$ & Yield $/ \%$ & $d r$ \\
\hline$p$-Tol & None & 72 & 6 & $5: 1$ \\
$p$-Tol & 2 & 5 & 77 & $4: 1$ \\
$p-\mathrm{NO}_{2} \mathrm{C}_{6} \mathrm{H}_{4}$ & None & 24 & 62 & $4: 1$ \\
$p-\mathrm{NO}_{2} \mathrm{C}_{6} \mathrm{H}_{4}$ & 2 & 2.5 & 87 & $3: 1$ \\
\hline
\end{tabular}

2009 年, Poli 课题组 ${ }^{[30]}$ 以多取代碳酸酯酰胺为底物, 用乙二亚砜作配体在 $\mathrm{Pd}(\mathrm{OAc})_{2}$ 催化下通过分子内烯丙 位氨化反应实现了噁嗪酮的构建(表 16). 研究表明，该 反应收率普遍不高，乙酸作溶剂时产率中等偏下，而二 表 16 钯催化碳酸酷酰胺分子内烯丙位 $\mathrm{C}-\mathrm{H}$ 活化、氨化反 应

Table $16 \mathrm{Pd}(\mathrm{OAc})_{2}$ catalyzed intramolecularly allyl $\mathrm{C}-\mathrm{H}$ activation and amination of carbonate amide

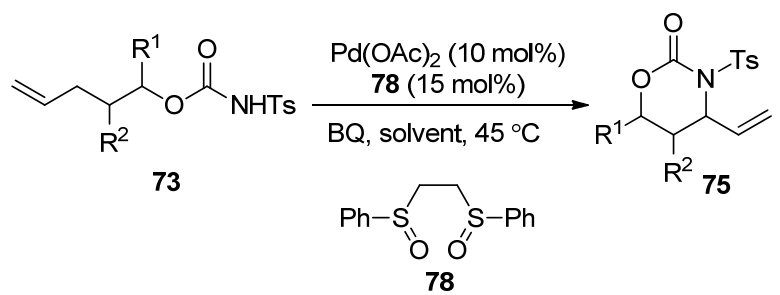

\begin{tabular}{|c|c|c|c|c|}
\hline $\mathrm{R}^{1}$ & $\mathrm{R}^{2}$ & Solvent & $d r$ & Yield $/ \%$ \\
\hline \multirow{2}{*}{$\mathrm{Me}$} & \multirow{2}{*}{$\mathrm{H}$} & $\mathrm{AcOH}$ & $83: 17$ & 65 \\
\hline & & $\mathrm{CH}_{2} \mathrm{Cl}_{2}$ & $\geqslant 95: 5$ & 12 \\
\hline \multirow{2}{*}{$i-\operatorname{Pr}$} & & $\mathrm{AcOH}$ & $89: 11$ & 67 \\
\hline & & $\mathrm{CH}_{2} \mathrm{Cl}_{2}$ & $72: 28$ & 10 \\
\hline \multirow{2}{*}{$n-\mathrm{Bu}$} & & $\mathrm{AcOH}$ & $74: 26$ & 62 \\
\hline & & $\mathrm{CH}_{2} \mathrm{Cl}_{2}$ & $\geqslant 95: 5$ & 8 \\
\hline \multirow{12}{*}{$\mathrm{H}$} & \multirow{2}{*}{$\mathrm{Bn}$} & $\mathrm{AcOH}$ & $63: 37$ & 57 \\
\hline & & $\mathrm{CH}_{2} \mathrm{Cl}_{2}$ & $60: 40$ & 35 \\
\hline & \multirow{2}{*}{$p$-Tol } & $\mathrm{AcOH}$ & $87: 13$ & 64 \\
\hline & & $\mathrm{CH}_{2} \mathrm{Cl}_{2}$ & $87: 13$ & 36 \\
\hline & \multirow{2}{*}{$\mathrm{Me}$} & $\mathrm{AcOH}$ & $67: 33$ & 54 \\
\hline & & $\mathrm{CH}_{2} \mathrm{Cl}_{2}$ & $50: 50$ & 22 \\
\hline & \multirow{2}{*}{$n$-Bu } & $\mathrm{AcOH}$ & $60: 40$ & 15 \\
\hline & & $\mathrm{CH}_{2} \mathrm{Cl}_{2}$ & $60: 40$ & 15 \\
\hline & \multirow{2}{*}{$\mathrm{Bn}$} & $\mathrm{AcOH}$ & $63: 37$ & 57 \\
\hline & & $\mathrm{CH}_{2} \mathrm{Cl}_{2}$ & $60: 40$ & 35 \\
\hline & \multirow{2}{*}{$\mathrm{Ph}$} & $\mathrm{AcOH}$ & $71: 29$ & 37 \\
\hline & & $\mathrm{CH}_{2} \mathrm{Cl}_{2}$ & $60: 40$ & 30 \\
\hline
\end{tabular}


氯甲烷作溶剂时则更低. 此外, 只有少量实例能实现较 高的非对映选择性, 部分实例中用乙酸作溶剂时产物的 非对映选择性比在二氯甲烷中略有提高.

2014 年, 顾振华课题组 ${ }^{[31]}$ 用 $\operatorname{Pd}(\mathrm{dba})_{2}$ 催化实现三氯 乙酰亚胺酯发生分子内 Tsuji-Trost 反应实现啞嗪的合 成, 产物经 $1 \mathrm{~mol} / \mathrm{L}$ 盐酸及 $1 \mathrm{~mol} / \mathrm{L} \mathrm{NaOH}$ 水解生成相应 的 1,3-氨基醇(Scheme 14). 研究发现, 叔丁基碳酸酯 (OBoc) 的离去性能最好, 反应收率普遍比较高, 产物以 顺式为主, 但是 $\mathrm{R}$ 基团位阻较大的话能实现更好的非对 映选择性，而小位阻基团的选择性相对差一些. 当以手 性高烯丙醇为起始原料, 经烯烃复分解、与三氯乙腈加 成制得相应的手性底物，最后经 $\operatorname{Pd}(\mathrm{dba})_{2}$ 催化转化得到
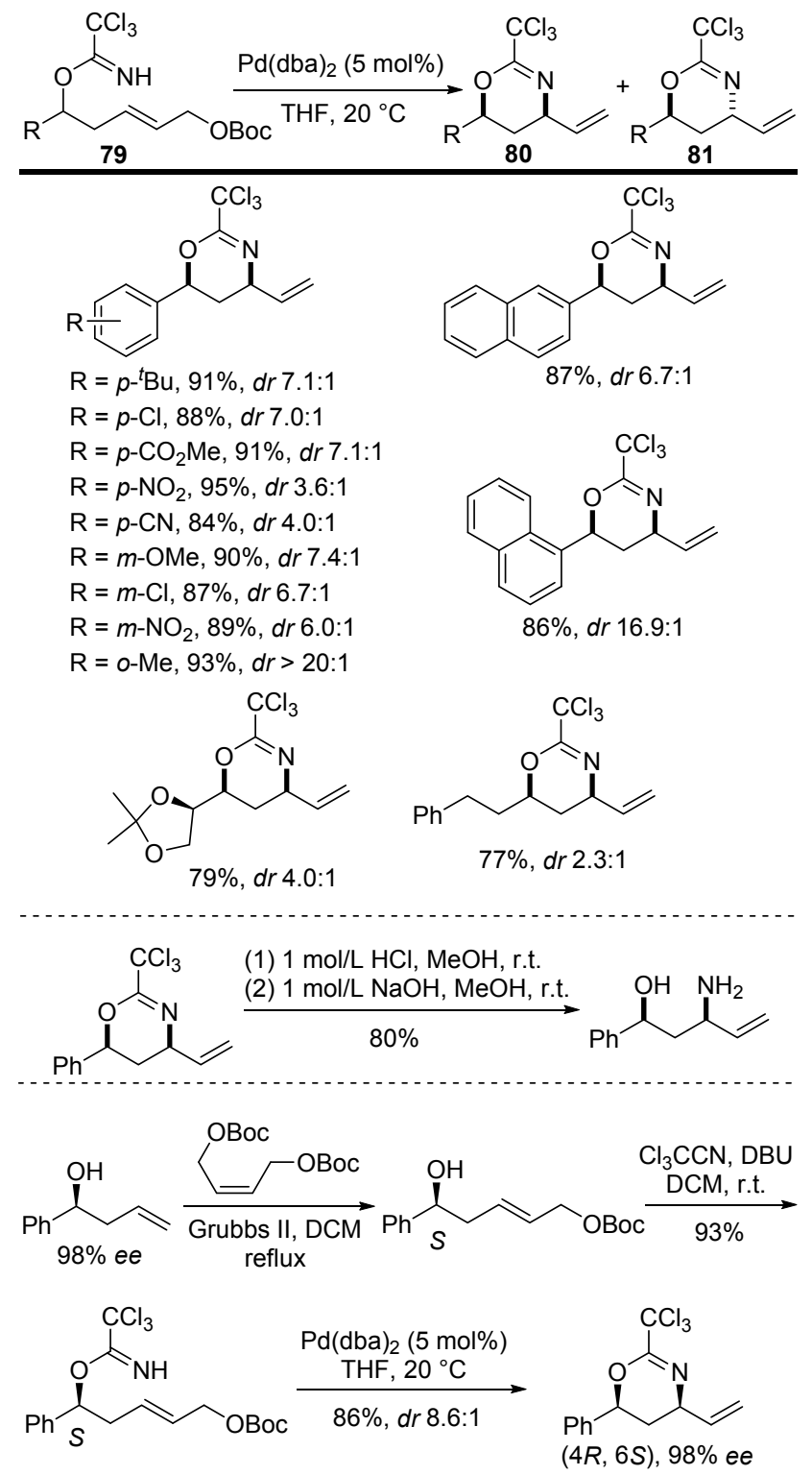

图式 14 钯催化三氯乙酰亚胺酯分子内 Tsuji-Trost 反应 Scheme $14 \operatorname{Pd}(\mathrm{dba})_{2}$ catalyzed intramolecular Tsuji-Trost reaction of trichloroacetimidate
目标化合物，反应保留了起始原料的 ee 值. 2019 年, White 课题组 ${ }^{[32]}$ 采用亚砜-噁唑啉配体 $(\mathrm{SOX}) 、 \mathrm{Pd}(\mathrm{OAc})_{2}$ 为催化剂催化氨基磺酸酯分子内烯丙位 $\mathrm{C}-\mathrm{H}$ 活化、氨 化反应，从而合成啞唾嗦(Scheme 15). 通过调节亚砜配 体与对苯二醌的组合可以实现顺、反产物的选择性合成: 富电子亚砜-噁唑啉配体 82 与 2,5-二甲基对二苯醌 (DMBQ)有利于 anti 产物的生成, 平均产率大约 $66 \%$, 而缺电子亚砜-噁唑啉配体 83 与对二苯醌(BQ)有利于 syn 产物的生成, 平均产率大约 $62 \%$. 以手性底物作为 起始原料，通过手性诱导，作者将该方法用于维生素 D3 衍生物的合成中.

\section{2 .3 铁催化 1,3 -氨基醇类化合物的合成}

2012 年, White 课题组 ${ }^{[33]}$ 以三价铁作为催化剂, 类 卟啉为配体, 通过分子内烯丙位 $\mathrm{C}-\mathrm{H}$ 氨化反应合成檼 唾嗦(oxathiazinane)(表 17). 相较传统使用的 $\mathrm{Rh}_{2}(\mathrm{OAc})_{4}$ 、 $\mathrm{Pd}(\mathrm{OAc})_{2}$ 等催化剂, 该反应所用的催化剂廉价无毒, 生 成的副产物 $\mathrm{N}$ 杂环丙烷也大大减少，顺式产物选择性更 好. 此外, 该催化体系还可以实现苄位氢的活化, 但反 应活性不如烯丙位.

\section{3 氮杂环的开环一加成反应}

氮杂三元环或四元环由于自身的环张力，利用过渡 金属或路易斯酸催化开环、与亲电试剂加成也是一种制 备氨基醇的方法.

\subsection{1 钯催化氮杂环丙烷开环制备 1,3 -氨基醇类化合 物}

2001 年, Tanaka 课题组 ${ }^{[34]}$ 利用 $\mathrm{Pd}\left(\mathrm{PPh}_{3}\right)_{4} / \mathrm{InI}$ 联合催 化，先通过 Pd 催化 2-乙炔基氮杂环丙烷开环、金属交 换转化为联烯基铟，然后再与醛进行亲核加成反应制得 1,3-氨基醇(Scheme 16). 通过底物的手性诱导可以得到 三个手性中心的目标化合物, 以炔基跟羟基处于 $s y n$ 构 型的产物为主，总体上收率中等偏下.

2001 年, Takemoto 课题组 ${ }^{[35]}$ 也采用 $\mathrm{Pd}\left(\mathrm{PPh}_{3}\right)_{4} / \mathrm{InI}$ 联 合催化剂合成了 2-乙烯基-1,3-氨基醇(表 18). 该反应首 先 InI 还原 2-乙烯基氮杂环丙烷开环经极性反转与 $\mathrm{Pd}\left(\mathrm{PPh}_{3}\right)_{4}$ 结合成烯丙基钯, 再与醛进行加成生成高烯 丙醇, 即 2-乙烯基-1,3-氨基醇. 作者认为反应可能经过 六元环椅式构象过渡态, 因此不管是顺式还是反式底 物，均以顺式 1,3-氨基醇为主要产物, $\mathrm{N}$ 上取代基对反应 有一定的影响, 其中 Mts 效果最好. 此外, 需要注意的 是，反应中还有部分烯丙胺(高烯丙醇)为副产物.

上述两类反应需要 1.3 或 2.0 equiv. 的 InI 作为还原 剂，该试剂昂贵的价格限制了该方法的应用，不利于该 反应的大规模应用. 


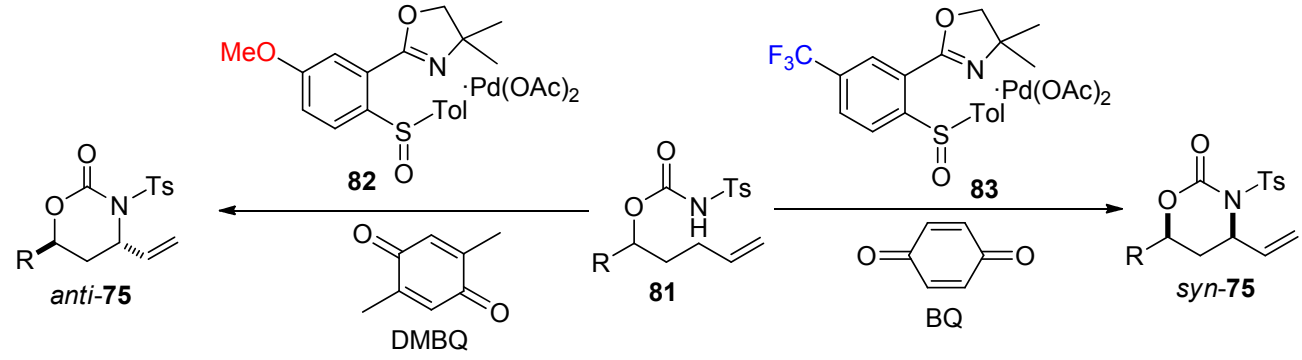<smiles>C=CC1CC(c2ccc3ccccc3c2)OC(=O)N1C</smiles>

$66 \%, 13.1: 1 d r$<smiles>C=CC1CC(c2ccccc2)OC(=O)N1[13I]</smiles>

$81 \%, 8.9: 1 d r$<smiles>C=CC1CC(C2CC2)OC(=O)N1[13I]</smiles>

$78 \%, 6.2: 1 d r$<smiles>C=CC1CC(C=C)N([13CH3])C(=O)O1</smiles><smiles>C=CC1CC(c2ccc3c(c2)CCN3[Na])OC(=O)N1[NH3+]</smiles>

$66 \%, 10: 1 d r$<smiles>C=C[C@@H]1CC(c2ccccc2Br)OC(=O)N1[13CH3]</smiles>

$75 \%, 20: 1 d r$<smiles>[3H]N1C(=O)OC(C2CCCC2)C[C@H]1C=C</smiles>

$68 \%, 8.1: 1 d r$<smiles>[3H]N1C(=O)OC(CCc2ccccc2)C[C@H]1C=C</smiles>

$68 \%, 8.1: 1 d r$<smiles>C=CC1CC(c2ccc3ccccc3c2)OC(=O)N1C</smiles><smiles>C=CC1CC(c2ccc(OC)cc2)OC(=O)N1[13I]</smiles><smiles>C=CC1CC(C2(c3ccccc3)CC2)OC(=O)N1[135I]</smiles>

70\%, 7.9:1 dr<smiles>C=CC1CC(CO)CCC1CO</smiles>

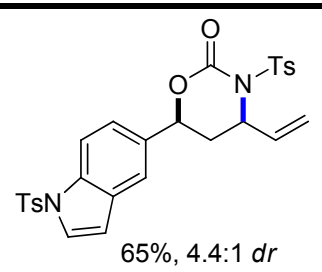<smiles>C=CC1CC(c2ccccc2Br)OC(=O)N1[13CH3]</smiles>

75\%, 20:1 dr<smiles>C=CC1CC(C2CCN(C(=O)OC(C)(C)C)CC2)OC(=O)N1[Te]</smiles><smiles>C=CC1CC(CCc2ccccc2)OC(=O)N1[AsH3-]</smiles>
$83 \%, 6.3: 1 d r$

图式 15 钯/亚砜-啞唑啉催化氨基磺酸酯分子内 $\mathrm{C}-\mathrm{H}$ 活化、氨化反应

Scheme $15 \mathrm{Pd}(\mathrm{OAc})_{2}-\mathrm{SOX}$ catalyzed intramolecular $\mathrm{C}-\mathrm{H}$ activation and amination of sulfamate

表 17 铁(III)催化氨基磺酸酯分子内 $\mathrm{C}-\mathrm{H}$ 活化、氨化反应

Table 17 Fe(III) catalyzed intramolecular $\mathrm{C}-\mathrm{H}$ activation and amination of sulfamate

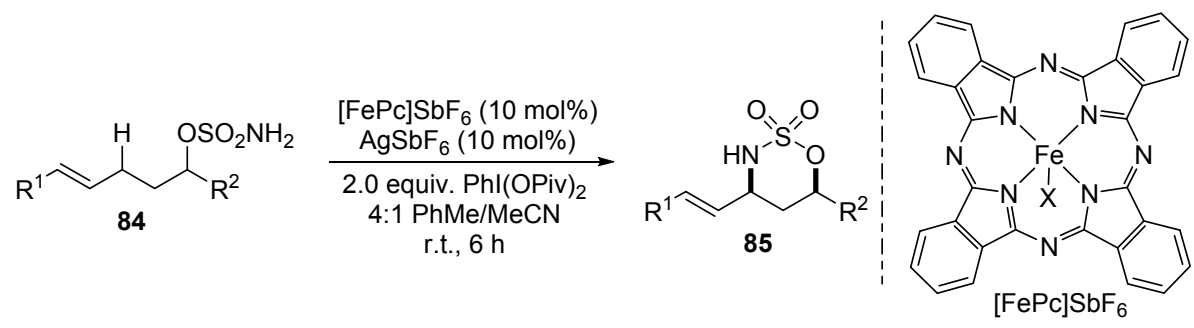

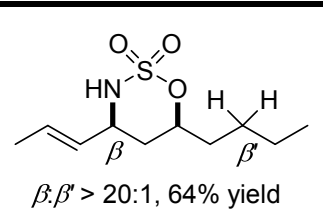

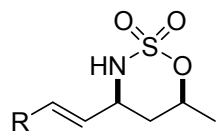

$\mathrm{R}=\mathrm{CO}_{2} \mathrm{Me}, \beta \cdot \beta^{\prime}-, 39 \%$ yield $\mathrm{R}=\mathrm{CH}_{2} \mathrm{OAc}, \beta \cdot \beta^{\prime}-, 47 \%$ yield

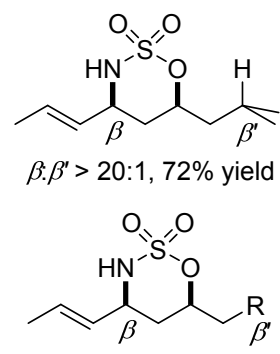

$\mathrm{R}=\mathrm{CO}_{2} \mathrm{Et}, \beta \cdot \beta^{\prime}-, 69 \%$ yield

$\mathrm{R}=\mathrm{CH}_{2} \mathrm{OAc}, \beta: \beta^{\prime}-, 61 \%$ yield

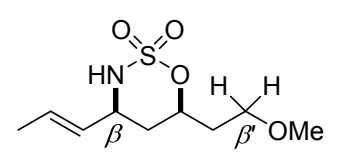

$\beta: \beta^{\prime}=7: 1,71 \%$ yield<smiles>CC=CC1CC(CC(C)C)OS(=O)(=O)N1</smiles>

$\beta: \beta^{\prime}=14: 1,55 \%$ yield

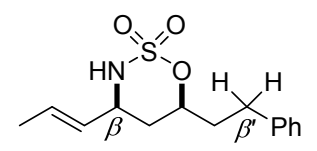

allic vs benzylic, $>20: 1$ $\beta: \beta^{\prime}=5: 1,62 \%$ yield<smiles>C/C=C/C1CC(CC(C)C2=C(C)CCCC2(C)C)OS(=O)(=O)N1</smiles>

$\beta . \beta^{\prime}>7: 1,53 \%$ yield 


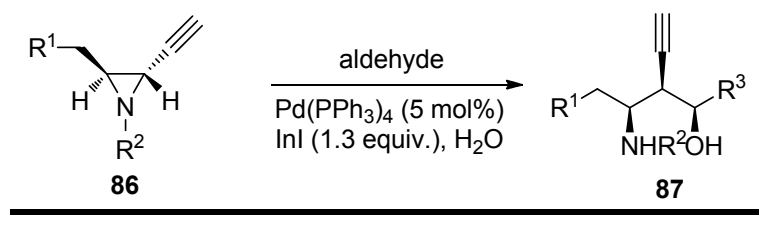

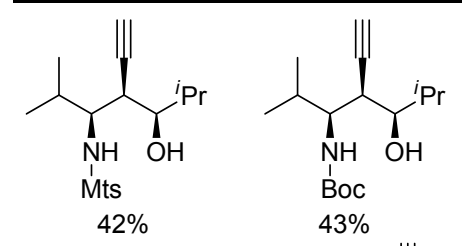

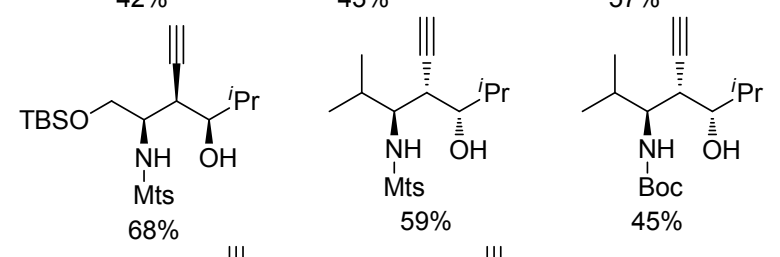

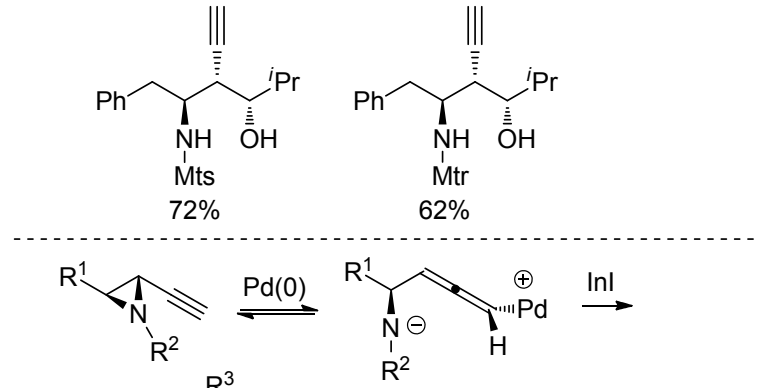

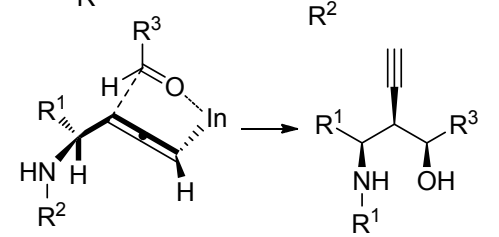

图式 $16 \mathrm{Pd}$ 催化乙炔基氮杂环丙烷与醛的加成反应 Scheme $16 \quad \mathrm{Pd}\left(\mathrm{PPh}_{3}\right)_{4}$ catalyzed addition of ethynylaziridine and aldehyde

1.3.2 硅氢还原氮杂环丙烷制备 1,3 -氨基醇类化合物 2018 年, Gansäuer 课题组 ${ }^{[36]}$ 将烯丙醇转化为羟基取
代的氮杂环丙烷，在 $\mathrm{TBAF}$ 作用下经 $\mathrm{PhSiH}_{3}$ 还原转化为 1,3-氨基醇, 当反应原料为仲胺得到反式产物(Scheme 17). 值得注意的是, 产物中 $\mathrm{R}^{3}$ 基团所在碳上的氢来自 于还原剂苯硅烷, 采用氝代硅烷将能方便地在该碳上引 入氛原子, 这对医药研发有着重要的意义.

1.3.3 路易斯酸催化氮杂环丙烷开环制备 1,3-氨基醇 类化合物

2020 年, 王川课题组 ${ }^{[37]}$ 报道了 $\mathrm{Zn}(\mathrm{OTf})_{2}$ 催化亲核 试剂对 2,3-听丙啶醇的亲核进攻从而制得 2,3-二氨基醇 产物，该反应具有良好的区域选择性，作者认为羟基的 导向作用使亲核试剂选择性进攻 3 位(Scheme 18), 在各 个底物中, 其区域选择性 C3：C2>98：2. 氨鲁米特与 雌素酮衍生在该反应中反应转化率也较好(最后两个例 子). 该反应中芳香胺普遍有中等偏上的转化率，但是 脂肪胺却未检测到目标化合物, 可能是由于脂肪胺碱性 较强导致 $\mathrm{Zn}(\mathrm{OTf})_{2}$ 无法催化反应的进行, 也有可能是所 用的溶剂乙酸乙酯不适合于脂肪胺的反应(可能优先生 成酰胺而非进攻氮杂环丙烷).

1.3.4 路易斯酸催化氮杂环丁烷开环制备 1,3-氨基醇 类化合物

2007 年, Ghorai 课题组 ${ }^{[38]}$ 以路易斯酸(如 $\mathrm{Cu}(\mathrm{OTf})_{2}$ 、 $\left.\mathrm{Zn}(\mathrm{OTf})_{2} 、 \mathrm{BF}_{3} \cdot \mathrm{OEt}_{2}\right)$ 为催化剂, 氮杂环丁烷可以开环与 羰基化合物发生 $[4+2]$ 反应生成 1,3-噁嗪啉, 经对甲苯 磺酸水解即可得到 1,3-氨基醇(表 19), 其中酮衍生的 1,3-啞嗪啉不稳定, 在后处理过程中就会水解成 1,3-氨 基醇. 该方法在非手性底物和非手性催化剂的情况下, 产物却表现出中等的 $e e$ 值. 作者认为, 中间体 int-1 的 分子内椅式加成是导致产物具有中等 $e e$ 值原因(Scheme 19). 该方法由于小环化合物原料本身制备较难, 因此 应用受到一定的限制.

表 $18 \mathrm{Pd}$ 催化乙烯基氮杂环丙烷与醛的加成反应

Table $18 \mathrm{Pd}\left(\mathrm{PPh}_{3}\right)_{4}$ catalyzed addition of vinylaziridine and aldehyde
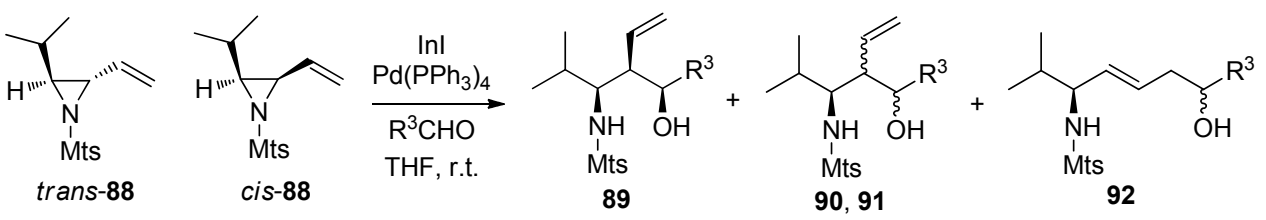

\begin{tabular}{|c|c|c|c|c|}
\hline Substrate & Aldehyde & Product & Yield/\% & Ratio $[89:(90+91): 92]$ \\
\hline tran-88 & $\mathrm{PhCHO}$ & $89 \sim 91 / 92$ & 86 & $80: 17: 3$ \\
\hline$c i s-\mathbf{8 8}$ & $\mathrm{PhCHO}$ & $89 \sim 91 / 92$ & 98 & $81: 15: 4$ \\
\hline$c i s-\mathbf{8 8}$ & $p-\mathrm{MeOC}_{6} \mathrm{H}_{4} \mathrm{CHO}$ & $89 \sim 91 / 92$ & 91 & $85: 13: 2$ \\
\hline$c i s-88$ & $p-\mathrm{ClC}_{6} \mathrm{H}_{4} \mathrm{CHO}$ & $89 \sim 91 / 92$ & 85 & $83: 16: 1$ \\
\hline cis-88 & $i$-BuCHO & $89 \sim 91 / 92$ & 97 & $85: 12: 3$ \\
\hline $\mathrm{R}={ }^{i} \mathrm{Pr}$ & $\mathrm{PhCHO}$ & $89 \sim 91 / 92$ & 58 & $79: 9: 12$ \\
\hline $\mathrm{R}=\mathrm{TBSOCH}_{2}$ & $\mathrm{PhCHO}$ & $89 \sim 91 / 92$ & 70 & $71: 13: 16$ \\
\hline $\mathrm{R}=\mathrm{Me}$ & $\mathrm{PhCHO}$ & $89 \sim 91 / 92$ & 65 & $52: 17: 31$ \\
\hline
\end{tabular}




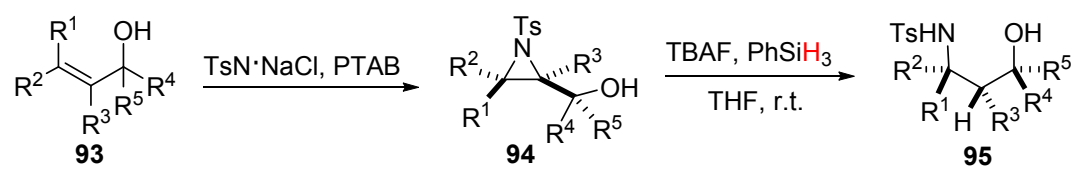
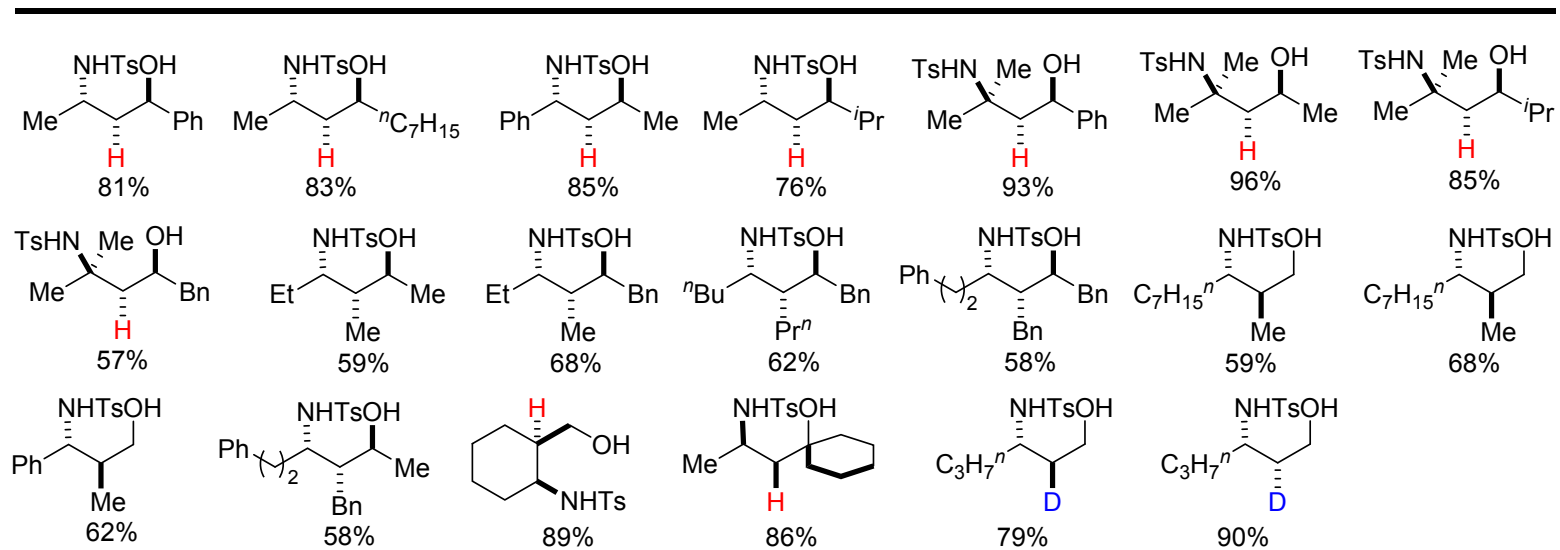

PTAB: phenyltrimethylammonium tribromide

图式 17 硅氢还原氮杂环丙烷衍生物

Scheme 17 Reduction of aziridine derivatives via silane
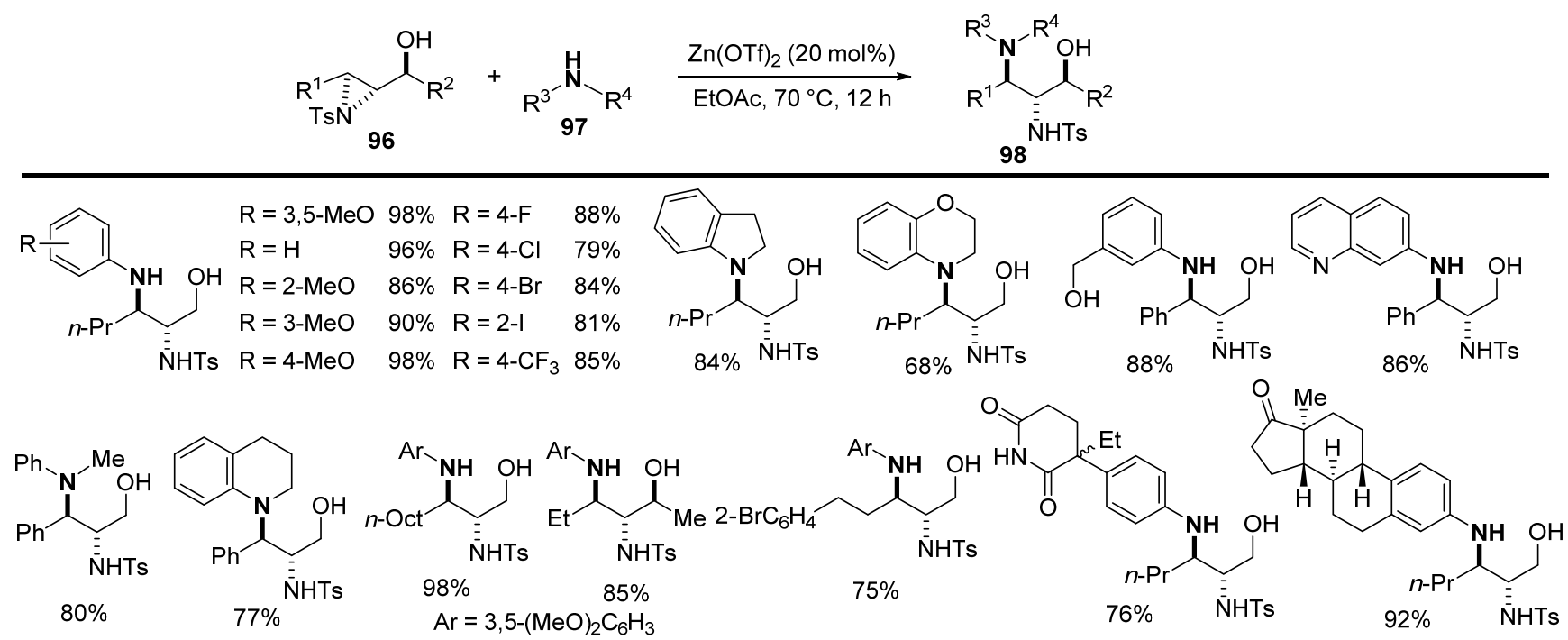

图式 $18 \mathrm{Zn}(\mathrm{II})$ 催化胺与氮杂环丙烷的加成反应

Scheme $18 \mathrm{Zn}(\mathrm{II})$ catalyzed addition of amine with aziridine derivatives

表 19 钯催化乙烯基氮杂环丙烷与醛的加成反应

Table $19 \mathrm{Pd}\left(\mathrm{PPh}_{3}\right)_{4}$ catalyzed addition of vinylaziridine and aldehyde

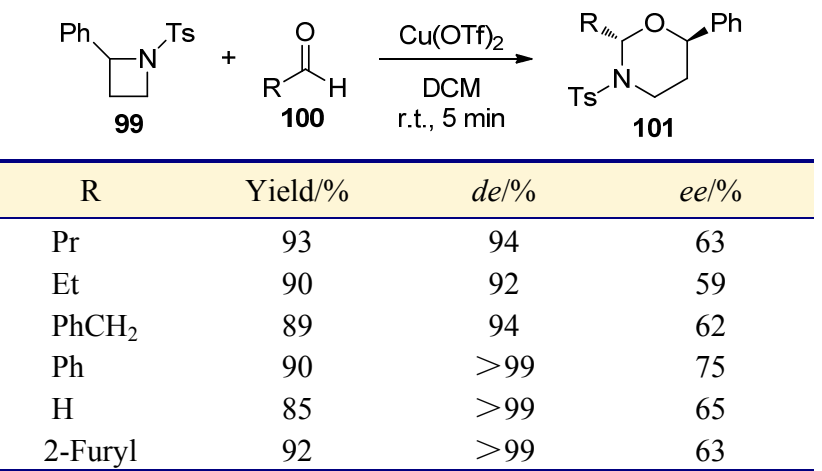

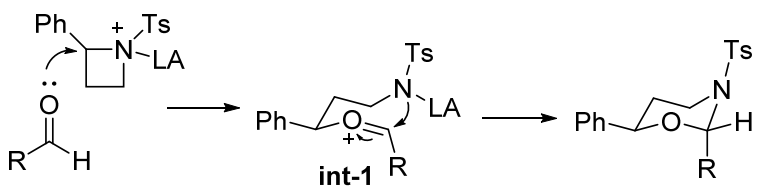

$\mathrm{Ph}$

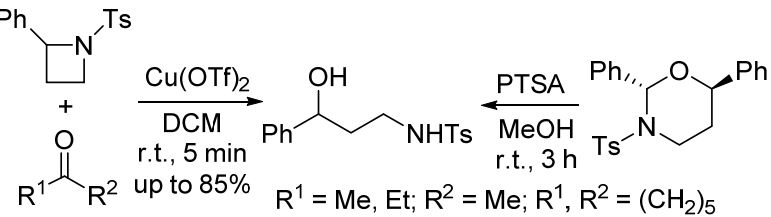

图式 19 氮杂环丁烷与醛的加成机理

Scheme 19 Mechanism of addition of $N$-Ts azetidine and aldehyde 


\subsection{5 $\beta$-内酰胺的还原制备 1,3-氨基醇}

2018 年, Kumar 课题组 ${ }^{[39]}$ 利用嗍烷还原 $\beta$-内酰胺为 1,3-氨基醇作为合成子(表 20), 用于合成更复杂的氮杂 环丁烷、噁嗪烷、三氮唑等的衍生物. 值得注意的是, 当 $\mathrm{R}$ 基团在芳环的邻位取代时无法得到预期的化合物.

表 $20 \beta$-内酰胺还原制备 1,3-氨基醇类化合物

Table 20 Reduction of $\beta$-lactams to 1,3-amino alcohols

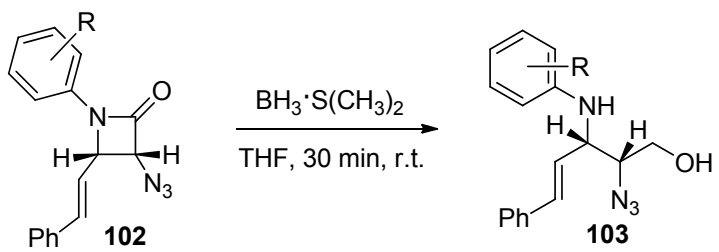

\begin{tabular}{lc}
\hline \multicolumn{1}{c}{$\mathrm{R}$} & Yield/\% \\
\hline $\mathrm{H}$ & 66 \\
$4-\mathrm{F}$ & 62 \\
$4-\mathrm{Cl}$ & 60 \\
$4-\mathrm{CH}_{3}$ & 65 \\
$4-\mathrm{MeO}$ & 58 \\
$2-\mathrm{Cl}$ & - \\
$2-\mathrm{CH}_{3}$ & - \\
\hline
\end{tabular}

\section{$1.4[3+2]$ 偶极环加成反应制备 1,3-氨基醇类化合物}

2014 年, 康彦虎课题组 ${ }^{[40]}$ 以 $N$-甲基硝酮与烯烃为 起始原料, 采用一种全新的策略——钉催化 $\mathrm{N}-\mathrm{O}$ 键断 裂、分子内自身氢转移一一实现啞嗪的合成(表 21). 虽 然该反应只有中等的收率，但能选择性地生成顺式产 物. 机理研究表明, 该反应首先是由 $N$-甲基硝酮与烯烃 经[3+2]环加成反应生成 $N$-甲基异恶唑烷, 而后在对繖 花烃二氯化钉二聚体 $\left(\left[\mathrm{RuCl}_{2}(p \text {-cymene })\right]_{2}\right)$ 催化下经 $\mathrm{N}$ $\mathrm{O}$ 键断裂、分子内自身氢转移生成目标化合物, 其中只 有顺式异恶唑烷能进行转化. 顺式异恶唑烷的生成量决 定了反应的收率, 由于脂肪端烯进行 $[3+2]$ 环加成效率 较低, 导致反应的收率偏低. 氝代实验研究表明, 亚甲 基上的氢 $\mathrm{OCH}_{2} \mathrm{NH}$ 来自于 $N-\mathrm{CH}_{3}$. 基于上述研究, 该课 题组直接将顺式 $N$-甲基异恶唑烷用于 $\left[\mathrm{RuCl}_{2}(p-\right.$ cymene) $]_{2}$ 催化转化 ${ }^{[41]}$ (表 22), 产率总体上普遍大于 $80 \%$.

值得说明的是, $N$-甲基硝酮进行反应优点在于所制 备的产物噁嗪烷可以方便地进行转化, 经 $\mathrm{LiAlH}_{4}$ 还原 生成 $N$-甲基胺, 经过盐酸差胺水解则制得 1,3-氨基醇, 收率普遍较高, 即 $N$-甲基可以选择性地保留或者脱除 (表 23).

由于难以通过手性配体诱导硝酮与端烯的 $[3+2]$ 环 加成反应选择性地转化为手性异恶唑烷, 因此该课题组 将这一方法应用于手性底物转化 ${ }^{[42]}$. 以手性甘油醛衍
表 21 钓催化分子内自身氢转移反应

Table $21\left[\mathrm{RuCl}_{2}(p \text {-cymene })\right]_{2}$ catalyzed intramolecular selfhydrogen transfer

$\left[\mathrm{RuCl}_{2}(p \text {-cymene })\right]_{2}(2.5 \mathrm{~mol} \%)$

表 22 钉催化 $N$-甲基异噁唑烷分子内自身氢转移反应 Table $22\left[\mathrm{RuCl}_{2}(p \text {-cymene })\right]_{2}$ catalyzed intramolecular selfhydrogen transfer of $N$-methylisoxazolidine

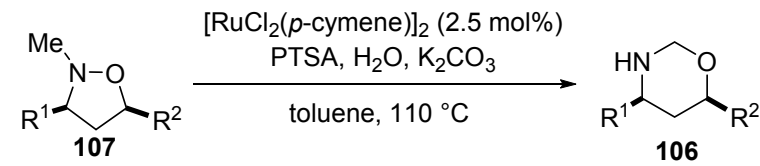

\begin{tabular}{llc}
\hline \multicolumn{1}{c}{$\mathrm{R}^{1}$} & \multicolumn{1}{c}{$\mathrm{R}^{2}$} & Yield $\%$ \\
\hline $\mathrm{PhCH}=\mathrm{CH}$ & $\mathrm{TBDPSOCH}_{2}$ & 82 \\
$\mathrm{C}_{4} \mathrm{H}_{9}$ & $\mathrm{C}_{6} \mathrm{H}_{13}$ & 95 \\
$\mathrm{C}_{3} \mathrm{H}_{7}$ & $\mathrm{Ph}$ & 77 \\
$\mathrm{PhCH}=\mathrm{CH}$ & $p-\mathrm{Tol}$ & 79 \\
$\mathrm{C}_{4} \mathrm{H}_{9}$ & $p-t-\mathrm{BuC}_{6} \mathrm{H}_{4}$ & 81 \\
$\mathrm{C}_{7} \mathrm{H} 15$ & $\mathrm{Ph}$ & 72 \\
$\mathrm{PhCH}=\mathrm{CH}$ & $p-\mathrm{MeOC}_{6} \mathrm{H}_{4}$ & 87 \\
$\mathrm{C}_{11} \mathrm{H}_{23}$ & $\mathrm{C}_{6} \mathrm{H}_{13}$ & 93 \\
$\mathrm{C}_{11} \mathrm{H}_{23}$ & $\mathrm{Ph}$ & 79 \\
$\mathrm{PhCH}=\mathrm{CH}$ & $\mathrm{AcOCH}$ & 90 \\
$\mathrm{C}_{11} \mathrm{H}_{23}$ & $\mathrm{PhCH}=\mathrm{CH}_{2}$ & 84 \\
$\mathrm{C}_{4} \mathrm{H}_{9}$ & $\mathrm{Ph}$ & 75 \\
$\mathrm{C}_{11} \mathrm{H}_{23}$ & $\mathrm{TBDPSOCH}$ & 91 \\
$\mathrm{C}_{9} \mathrm{H}_{19}$ & $\mathrm{Ph}$ & 81 \\
\hline
\end{tabular}


表 23 1,3-噁嗪烷的转化

Table 23 Transformation of 1,3-oxazine

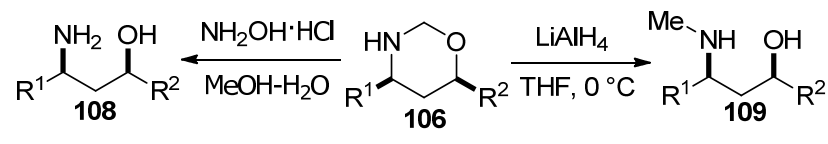

\begin{tabular}{|c|c|c|}
\hline $\mathrm{R}^{1}$ & $\mathrm{R}^{2}$ & Yield/\% \\
\hline $\mathrm{C}_{11} \mathrm{H}_{23}$ & $\mathrm{C}_{6} \mathrm{H}_{13}$ & 96 \\
\hline $\mathrm{PhCH}=\mathrm{CH}$ & $\mathrm{TBDPSOCH}_{2}$ & 70 \\
\hline $\mathrm{PhCH}=\mathrm{CH}$ & $\mathrm{AcOCH}_{2}$ & 87 \\
\hline & & 86 \\
\hline $\mathrm{C}_{11} \mathrm{H}_{23}$ & $\mathrm{C}_{6} \mathrm{H}_{13}$ & 92 \\
\hline $\mathrm{PhCH}=\mathrm{CH}$ & PMP & 84 \\
\hline $\mathrm{C}_{11} \mathrm{H}_{23}$ & $\mathrm{PhCH}=\mathrm{CH}$ & 90 \\
\hline $\mathrm{Me}$ & & 93 \\
\hline
\end{tabular}

生硝酮和芳基端烯为底物, $5 \mathrm{~mol} \%\left[\mathrm{RuCl}_{2}(p \text {-cymene })\right]_{2}$ 催化一锅法制备手性噁嗪烷(表 24), 总体上该反应收率 较非手性硝酮底物转化率高, 可能是手性底物更有利于 顺式中间体的生成, 所得产物为单一构型. 研究发现, 富电子端烯收率稍略低一些. 该方法被应用于生物活性 分子(一)-HPA-12 的不对称合中, 最终制得 $1.2 \mathrm{~g}$ 目标化 合物, ee 值为 $99.6 \%$, 具有目前该生物活性分子各种合 成方法中最高的光学纯度 (Scheme 20).

表 24 钉催化手性 $N$-甲基异噁唑烷分子内自身氢转移反应 Table $24\left[\mathrm{RuCl}_{2}(p \text {-cymene })\right]_{2}$ catalyzed intramolecular selfhydrogen transfer of chiral $N$-methylisoxazolidine

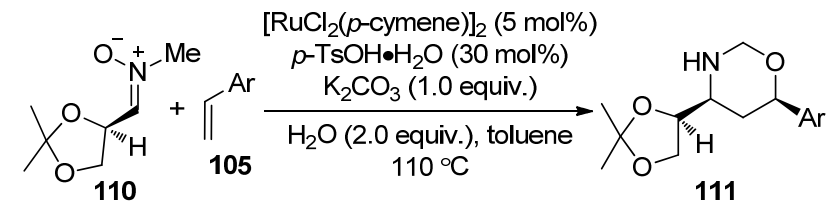

\begin{tabular}{lc}
\hline \multicolumn{1}{c}{$\mathrm{Ar}$} & Yield $/ \%$ \\
\hline $\mathrm{Ph}$ & 70 \\
$4-\mathrm{MeC}_{6} \mathrm{H}_{4}$ & 79 \\
$4-t-\mathrm{BuC}_{6} \mathrm{H}_{4}$ & 70 \\
$4-\mathrm{BrC}_{6} \mathrm{H}_{4}$ & 71 \\
$4-\mathrm{MeOC}_{6} \mathrm{H}_{4}$ & 64 \\
$4-\mathrm{FC}_{6} \mathrm{H}_{4}$ & 84 \\
$3-\mathrm{ClC}_{6} \mathrm{H}_{4}$ & 84 \\
$4-\mathrm{Cl}_{2} \mathrm{C}_{6} \mathrm{H}_{3}$ & 69 \\
$1-\mathrm{Naphthyl}$ & 78 \\
$\mathrm{BnOCH}_{2}$ & 70 \\
\hline
\end{tabular}

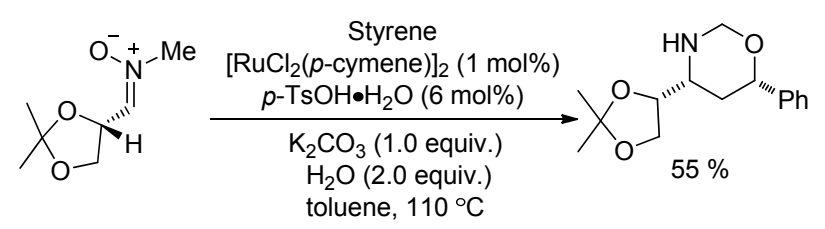

(a) $\mathrm{C}_{11} \mathrm{H}_{23} \mathrm{COCl}$
$\underset{\text { (b) } 60 \% \mathrm{AcOH}, \mathrm{HCl}}{\stackrel{\mathrm{NaIO}_{4}, \mathrm{NaBH}_{4}}{\longrightarrow}}$

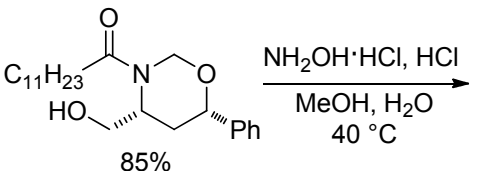

$$
\text { (-)-HPA-12,1.2 g }
$$

图式 20 不对称合成( - - -HPA-12

Scheme 20 Asymmetric synthesis of $(-)$-HPA-12

\section{5 其他制备 1,3-氨基醇类化合物的方法}

1.5.1 手性硒催化 $O$-烯丙基肟分子内亲电加成制备 1,3-氨基醇类化合物

2001 年, Tiecco 课题组 ${ }^{[43]}$ 采用手性 $\mathrm{Se}$-芳基三氟甲 烷磺酸硒促进 $O$-烯丙基肟分子内亲电关环反应(表 25), 得到 4-芳基硒异噁唑啉烷. 其中芳基三氟甲烷磺酸硒由 联硒与 $\mathrm{Br}_{2}+\mathrm{AgOTf}$ 现制而得. 在 $-70{ }^{\circ} \mathrm{C}$ 或 $-50{ }^{\circ} \mathrm{C}$ 下, 芳基三氟甲烷磺酸硒作为强路易斯酸活化分子内 $\mathrm{C}=\mathrm{C}$, 而后发生分子内亲电开环反应得到 4-芳基硒异噁唑啉 烷. $\mathrm{O}$ 上取代基为烯丙基时为 endo 加成产物, 而为高烯 丙基时为 exo 加成产物. 研究表明, 底物中 3-戊酩肜产 率相对较高, 选择性也好. 烯基上的取代基对反应的产 率及选择性影响不大. 所得的 4-芳基硒异噁唑啉烷经 $\mathrm{Zn} / \mathrm{AcOH}$ 还原得 2-硒基-1,3-氨基醇, 经 $\mathrm{Ph}_{3} \mathrm{SnH} / \mathrm{AIBN}$ 还原则可脱除硒基，据此可以方便地对其进行衍生化 (Scheme 21).

1.5.2 分子内 Michael 加成制备 1,3-氨基醇类化合物

2003 年, Gais 课题组 ${ }^{[4]}$ 利用分子内手性传递, 以 $\alpha, \beta$-不饱和亚磺酰亚胺(sulfoximine)为底物经过 1,4-加成 反应合成 1,3-噁嗪酮(Scheme 22). 该方法具有收率高选 择性好的优点, 1,3-噁嗪酮水解即可得到 1,3-氨基醇. 另 外, 利用亚磺酰亚胺基团的强吸电子能力, 可以非常方 便地进行衍生化, 而亚磺酰亚胺基团能通过 Ra-Ni 还原 进行脱除(图中产物均由衍生而得).

1.5.3 缺电子 $N$-烷基化合物对环氧乙烷的加成制备 1,3 - 氨基醇类化合物

2005 年, Murai 课题组 ${ }^{[45]}$ 将硫代酰胺用于 1,3 -氨基 醇的合成中. 该方法中, 通过硫代酰胺的双锂化及对环 氧化合物的亲核取代、开环, 再经硫代酰胺水解或氢化 铝锂还原即可制得目标化合物(表 26). 以手性环氧化合 
表 $25 O$-烯丙基肟分子内加成反应

Table 25 Intramolecular addition of $O$-alkenyl oxime

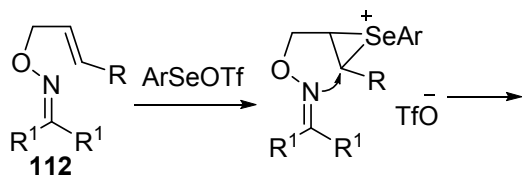<smiles>[Y5][R17](=O)C([R17])=O</smiles>

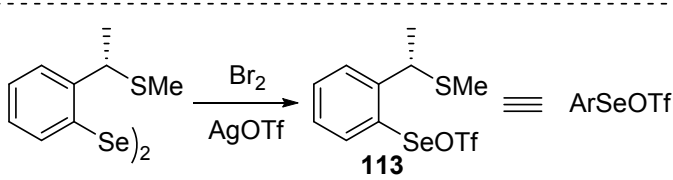

$$
\text { Entry }
$$<smiles></smiles><smiles>N=C1CCCCC1</smiles><smiles>CCCON=C(CCC)C(C)C</smiles><smiles></smiles><smiles>C=C([PH2+])[In]</smiles><smiles></smiles><smiles>CCCC(=NOCC)C(C)CC</smiles><smiles>C/C=C\C(=N/OCCC)C(C)C</smiles>

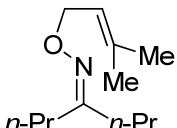

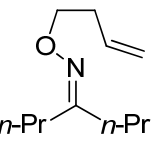

63

77

$88: 12$
物为底物则可衍生得到手性产物, 但该反应的选择性较 差.

2017 年, Malcolmson 课题组 ${ }^{[46]}$ 利用 $N$-烷基亚胺的 弱酸性, 经 LiHMDS 脱质子后再与环氧乙烷亲核加成制 得顺式 1,3-氨基醇(表 27). 研究表明, 环氧乙烷上的取

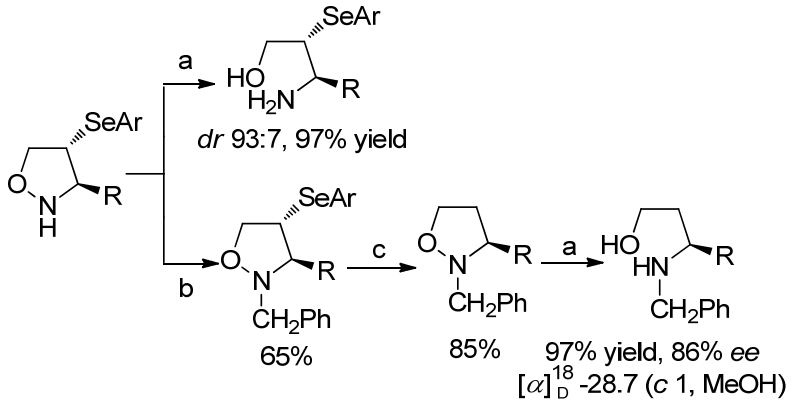

Reagents and conditions: (a) $\mathrm{Zn}, \mathrm{AcOH}, \mathrm{H}_{2} \mathrm{O}$; (b) $\mathrm{PhCH}_{2} \mathrm{Br}, \mathrm{Et}_{3} \mathrm{~N}$, $\mathrm{CH}_{2} \mathrm{Cl}_{2}$; (c) $\mathrm{Ph}_{3} \mathrm{SnH}$, AIBN, refluxing $\mathrm{C}_{6} \mathrm{H}_{6}$

图式 21 4-芳基硒异噁唑啉烷的转化

Scheme 21 Transformation of 4-aryl isooxazoline

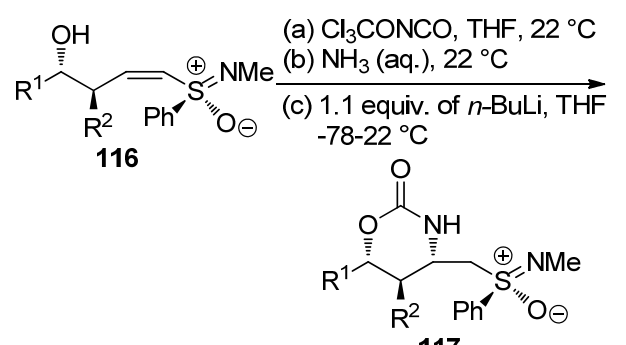

a: $R^{2}={ }^{i} \operatorname{Pr}, R^{1}=M e, 94 \%, \geq 98 \% d e$ b: $R^{2}=\mathrm{Me}, \mathrm{R}^{1}=\mathrm{Et}, 93 \%, \geq 98 \%$ de

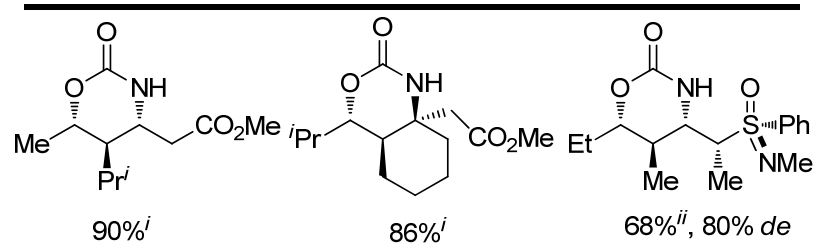<smiles>CCCC1C(C)NC(=O)OC1C</smiles>

$88 \%{ }^{i i}$<smiles>CCCC1NC(=O)OC(C)C1CC</smiles>

$79 \%{ }^{i i}$<smiles>CC(C)C1OC(=O)NC2(C)CCCCC12</smiles>

$90 \%$ ii i: (1) 2.2 equiv. of $n \mathrm{BuLi}, \mathrm{THF},-78^{\circ} \mathrm{C}$; (2) $\mathrm{ClCO}_{2} \mathrm{Me},-78^{\circ} \mathrm{C}, 4 \mathrm{~h}$

ii: (1) $\mathrm{MeCHO}$, Mel or $\mathrm{BnOCH}_{2} \mathrm{Cl}, \mathrm{THF},-78^{\circ} \mathrm{C}$; (2) Ra-Ni, THF, $\mathrm{H}_{2} \mathrm{O}$, $22{ }^{\circ} \mathrm{C}, 5 \sim 18 \mathrm{~h}$

图式 $22 \alpha, \beta$-不饱和亚磺酰亚胺衍生物的分子内 1,4-加成反应 Scheme 22 Intramolecular 1,4-addition of $\alpha, \beta$-unsaturated sulfoximine derivatives

代基位阻大小对反应的产率影响比较大，当 $\mathrm{R}^{2}$ 基团较 大时产率偏低; 另外，低温有利于提高 $d r$ 值.

1.5.4 铑催化 $\beta$-羰基烯胺不对称加氢制备 1,3 -氨基醇 类化合物

2009 年, 张绪穆 ${ }^{[47]}$ 课题组利用铑催化剂 $[\mathrm{Rh}(\mathrm{cod})-$ duanphos] $\mathrm{BF}_{4}$ 催化对 $\beta$-羰基烯胺的加氢, 实现了 $N$-乙酰 氨基 1,3-氨基醇的合成(表 28). 室温下 $1 \mathrm{~mol} \%$ 催化剂用 量即可实现非常高的收率及选择性. 作者主要研究了 $\mathrm{R}^{1}$ 为芳基的底物，其为脂肪基(如甲基)时同样有着高选 择性和高收率. 
表 26 硫代酰胺与醛的加成反应

Table 26 Addition of thioamide and aldehyde<smiles>[R]C(=S)NCc1ccccc1</smiles>

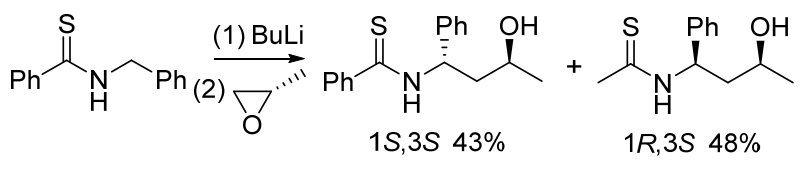

\begin{tabular}{llcc}
\hline \multicolumn{1}{c}{$\mathrm{R}^{1}$} & \multicolumn{1}{c}{$\mathrm{R}^{2}$} & anti/syn & Yield/\% \\
\hline$t-\mathrm{Bu}$ & $\mathrm{Me}$ & $44: 56$ & 90 \\
$4-\mathrm{FC}_{6} \mathrm{H}_{4}$ & $\mathrm{Me}$ & $48: 52$ & 80 \\
$\mathrm{Ph}$ & $\mathrm{MeOCH}{ }_{2}$ & $53: 47$ & 79 \\
$\mathrm{Ph}$ & $\mathrm{ClCH}_{2}$ & $57: 43$ & 94 \\
$\mathrm{Ph}$ & $\mathrm{HOCH}_{2}$ & $19: 81$ & 48 \\
$\mathrm{Ph}$ & $t$ - $\mathrm{Bu}$ & $14: 86$ & 83 \\
\hline
\end{tabular}

表 27 强碱作用下亚胺与环氧化合物的加成反应

Table 27 Strong base promoted addition of imine and epoxide
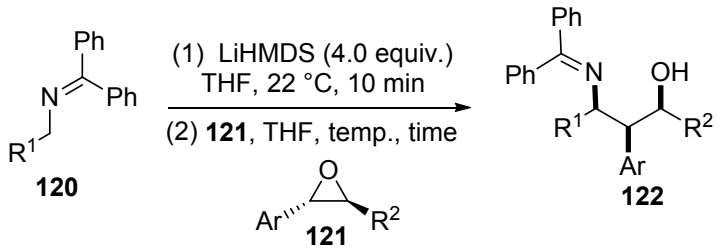

122

\begin{tabular}{|c|c|c|c|c|c|c|}
\hline $\mathrm{Ar}$ & $\mathrm{R}^{1}$ & $\mathrm{R}^{2}$ & $T /{ }^{\circ} \mathrm{C}$ & $t / \mathrm{h}$ & Yield/\% & $\begin{array}{c}d r(s y n: \\
a n t i)\end{array}$ \\
\hline $4-\mathrm{MeOC}_{6} \mathrm{H}_{4}$ & ${ }_{4} \mathrm{Ph}$ & $\mathrm{Me}$ & -45 & 4 & 94 & $9.0: 1$ \\
\hline $4-\mathrm{CF}_{3} \mathrm{C}_{6} \mathrm{H}_{4}$ & $\mathrm{Ph}$ & $\mathrm{Me}$ & -78 & 24 & 73 & $16.0: 1$ \\
\hline $4-\mathrm{CNC}_{6} \mathrm{H}_{4}$ & $\mathrm{Ph}$ & $\mathrm{Me}$ & -78 & 24 & $>98$ & $>20: 1$ \\
\hline $4-\mathrm{BrC}_{6} \mathrm{H}_{4}$ & $\mathrm{Ph}$ & $\mathrm{Me}$ & -78 & 48 & 77 & $14.5: 1$ \\
\hline $3-\mathrm{MeC}_{6} \mathrm{H}_{4}$ & $\mathrm{Ph}$ & $\mathrm{Me}$ & -60 & 24 & 67 & $11.0: 1$ \\
\hline $3-\mathrm{BrC}_{6} \mathrm{H}_{4}$ & $\mathrm{Ph}$ & $\mathrm{Me}$ & -60 & 27 & 81 & $8.0: 1$ \\
\hline $2-\mathrm{MeC}_{6} \mathrm{H}_{4}$ & $\mathrm{Ph}$ & $\mathrm{Me}$ & -45 & 48 & 78 & $9.5: 1$ \\
\hline $2-\mathrm{BrC}_{6} \mathrm{H}_{4}$ & $\mathrm{Ph}$ & $\mathrm{Me}$ & -45 & 24 & 73 & $7.0: 1$ \\
\hline $\mathrm{Ph}$ & $\mathrm{Ph}$ & $n-\mathrm{Bu}$ & -60 & 24 & 57 & $7.0: 1$ \\
\hline $\mathrm{Ph}$ & $\mathrm{Ph}$ & $\mathrm{CH}_{2} \mathrm{OTBS}$ & -45 & 24 & 92 & $13.5: 1$ \\
\hline $\mathrm{Ph}$ & $\mathrm{Ph}$ & $i-\operatorname{Pr}$ & -45 & 48 & 43 & $>20: 1$ \\
\hline $\mathrm{Ph}$ & $\mathrm{Ph}$ & $\mathrm{CH}_{2} \mathrm{OTBS}$ & -60 & 24 & 67 & $16.5: 1$ \\
\hline $4-\mathrm{CNC}_{6} \mathrm{H}_{4}$ & 3-Pyridyl & $\mathrm{Me}$ & -45 & 24 & 92 & $13.5: 1$ \\
\hline $4-\mathrm{CNC}_{6} \mathrm{H}_{4}$ & Vinyl & $\mathrm{Me}$ & -45 & 48 & 43 & $>20: 1$ \\
\hline$\underline{4-\mathrm{CNC}_{6} \mathrm{H}_{4}}$ & TBSC $\equiv \mathrm{C}$ & $\mathrm{Me}$ & -60 & 24 & 67 & $16.5: 1$ \\
\hline
\end{tabular}

\subsection{5 铜催化 1,3 -氨基醇类化合物的合成}

2016 年, Hartwig 课题组 ${ }^{[48]}$ 研究了 $\mathrm{Cu}\left(\mathrm{PPh}_{3}\right) \mathrm{H}$ 催化 未活化不对称内烯氢化氨化反应(Scheme 23). 在该方 法中, 大部分底物转化率中等偏上, 非对映选择性非常 高, 大部分 $e e$ 值都大于 $95 \%$. 作者尝试了 2,4,6-三氯苯 甲酰氧基、芳醚及吡啶酚醚等作为导向基团, 总体上对 反应产率影响不大, 其中 2,4,6-三氯苯甲酰氧基极易被 脱除，因此作者主要研究了该类底物的转化. 研究还发
表 28 铑催化 $\beta$-羰基烯胺加氢反应

Table $28[\mathrm{Rh}(\mathrm{cod})$ duanphos $] \mathrm{BF}_{4}$ catalyzed hydrogenation of $\beta$-carbonyl enamine

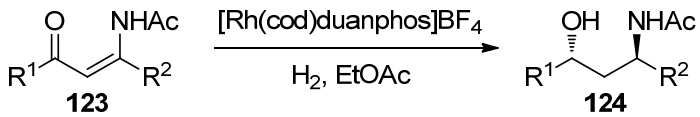

\begin{tabular}{lccccc}
\hline \multicolumn{1}{c}{$\mathrm{R}^{1}$} & $\mathrm{R}^{2}$ & $P_{\mathrm{H}_{2}}$ & Yield/\% & ee/\% & $d r($ syn $:$ anti $)$ \\
\hline $\mathrm{Ph}$ & $\mathrm{Me}$ & 20 & 100 & 99 & $5: 95$ \\
$p-\mathrm{MeC}_{6} \mathrm{H}_{4}$ & $\mathrm{Me}$ & 100 & 97 & 97 & $7: 93$ \\
$p-\mathrm{MeOC}_{6} \mathrm{H}_{4}$ & $\mathrm{Me}$ & 100 & 95 & 95 & $8: 92$ \\
$p-\mathrm{FC}_{6} \mathrm{H}_{4}$ & $\mathrm{Me}$ & 20 & 100 & 97 & $4: 96$ \\
$p-\mathrm{ClC}_{6} \mathrm{H}_{4}$ & $\mathrm{Me}$ & 20 & 100 & 99 & $4: 96$ \\
$p-\mathrm{BrC}_{6} \mathrm{H}_{4}$ & $\mathrm{Me}$ & 100 & 95 & 98 & $6: 94$ \\
$p-t \mathrm{BuC}_{6} \mathrm{H}_{4}$ & $\mathrm{Me}$ & 100 & 96 & 97 & $8: 92$ \\
$p-\mathrm{CyC}_{6} \mathrm{H}_{4}$ & $\mathrm{Me}$ & 100 & 93 & 97 & $8: 92$ \\
$m-\mathrm{MeC}_{6} \mathrm{H}_{4}$ & $\mathrm{Me}$ & 20 & 100 & 99 & $4: 96$ \\
$o-\mathrm{MeC}_{6} \mathrm{H}_{4}$ & $\mathrm{Me}$ & 20 & 100 & 94 & $14: 86$ \\
$\mathrm{Thiophen}-2-\mathrm{yl}$ & $\mathrm{Me}$ & 20 & 100 & 99 & $5: 95$ \\
$2-\mathrm{Naphthyl}$ & $\mathrm{Me}$ & 20 & 100 & 97 & $<1: 99$ \\
$\mathrm{Ph}$ & $\mathrm{Et}$ & 20 & 100 & 96 & $5: 95$ \\
Me & $\mathrm{Me}$ & 20 & 100 & 96 & $<1: 99$ \\
\hline
\end{tabular}

现，环状底物双键的电子效应、立体效应对反应的选择 性有着决定性作用.

\subsection{6 金催化 1,3-氨基醇类化合物的合成}

2016 年, Pu Lin 课题组 ${ }^{[49]}$ 采用 $\mathrm{Au}$ 催化炔丙胺与水 的加成实现 2-氨基酮的制备(Scheme 24). 底物上的磷酰 基作为亲核试剂, 进攻被 $\mathrm{NaAuCl}_{4}$ 活化的炔基, 以利于 $\mathrm{H}_{2} \mathrm{O}$ 的加成. 以手性底物为原料, 其 $e e$ 值在反应后得到 保持. 总体上, 该反应底物比较容易制备, 但反应收率 偏低, 产物极易转化为 1,3 -氨基醇.

\section{2 总结与展望}

由于含 1,3-氨基醇结构在天然产物及活性生物分子 结构的广泛存在, 其合成方法的开发具有重要的意义. 经过长期发展, 尤其是近 20 年的开发, 1,3-氨基醇的合 成方法研究已然得到长足发展, 无论是通过 aldol 缩合 或 $a z o-$ aldol 缩合, 还是通过过渡金属催化 $\mathrm{C}-\mathrm{H}$ 键活 化、氨化反应，或者利用氮杂环的开环一加成，抑或利用 $[3+2]$ 偶极环加成反应进行转化合成, 人们已经开发了 丰富多样的方法来实现不同结构 1,3-氨基醇的合成.

但各种合成方法自身的局限性依然存在: (1)有些手 性诱导基团自身难以制备，价格昂贵，在反应后难以回 收，因此大大增加了反应的应用成本. (2)由于有机小分 子催化剂自身的特点, 它能实现的底物往往局限于较活 泼的醛、酮, 底物范围非常窄, 难以拓展应用. (3)过渡金 属催化合成反应中所用的催化剂往往需要使用 $\mathrm{Rh} 、 \mathrm{Pd}$ 、 $\mathrm{Pt} 、 \mathrm{Au}$ 等贵金属的络合物，成本高昂且难以回收. 


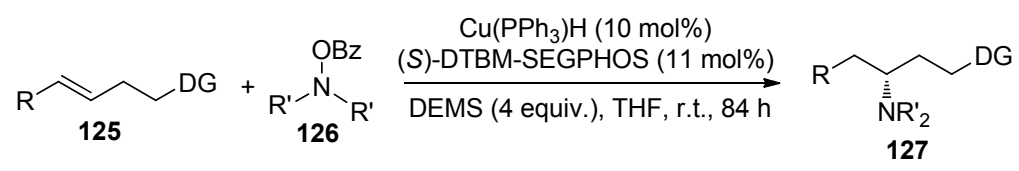

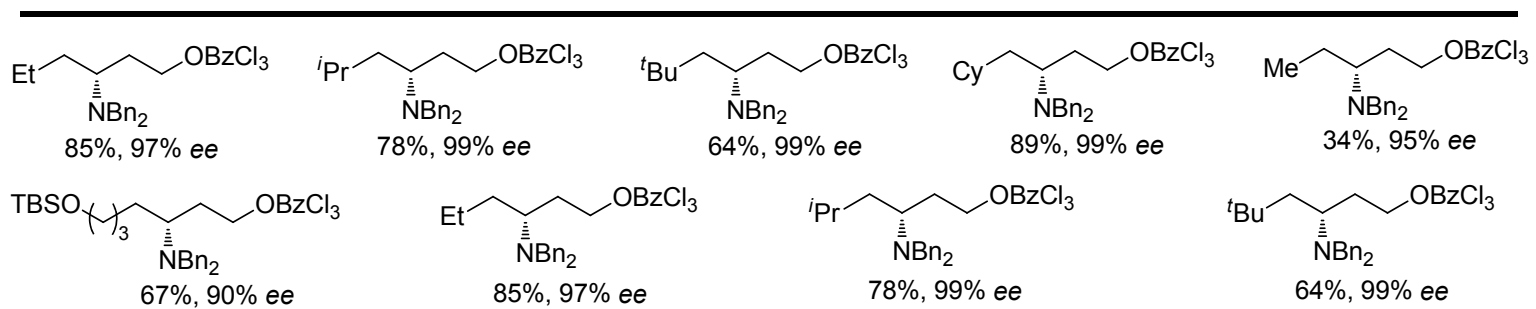

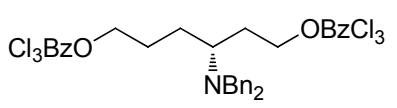

$90 \%, 98 \%$ ee<smiles>CC=CCCC(CCCCCCCC(C)(C)C)CCOC(C)(C)C</smiles>

$59 \%, 98 \%$ ee

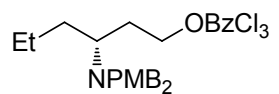

$60 \%, 97 \%$ ee

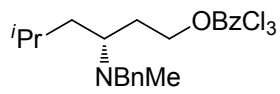

$56 \%$, >99\% ee

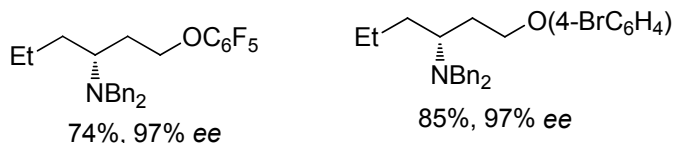<smiles>CCCC(CC)CCOc1ccccc1-c1nc2c(s1)CCC=C2</smiles>

$78 \%, 99 \%$ ee<smiles>CCCC(CC)CCOc1cncc(Cl)c1</smiles>

$78 \%, 99 \%$ ee

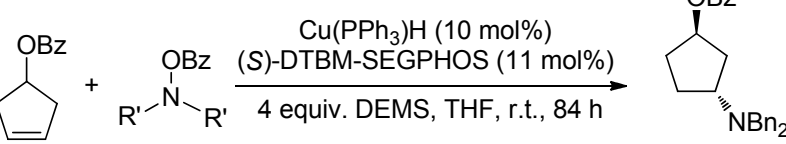

$$
\begin{aligned}
& 52 \% \text { yield, } 79 \% \text { conv. } \\
& >\text { 95:5 trans:cis }
\end{aligned}
$$

图式 $23 \mathrm{Cu}\left(\mathrm{PPh}_{3}\right) \mathrm{H}$ 催化高烯丙醇酯的不对称氢化、氨化

Scheme $23 \mathrm{Cu}\left(\mathrm{PPh}_{3}\right) \mathrm{H}$ catalyzed asymmetric hydrogenation and amination of homoallylic ester
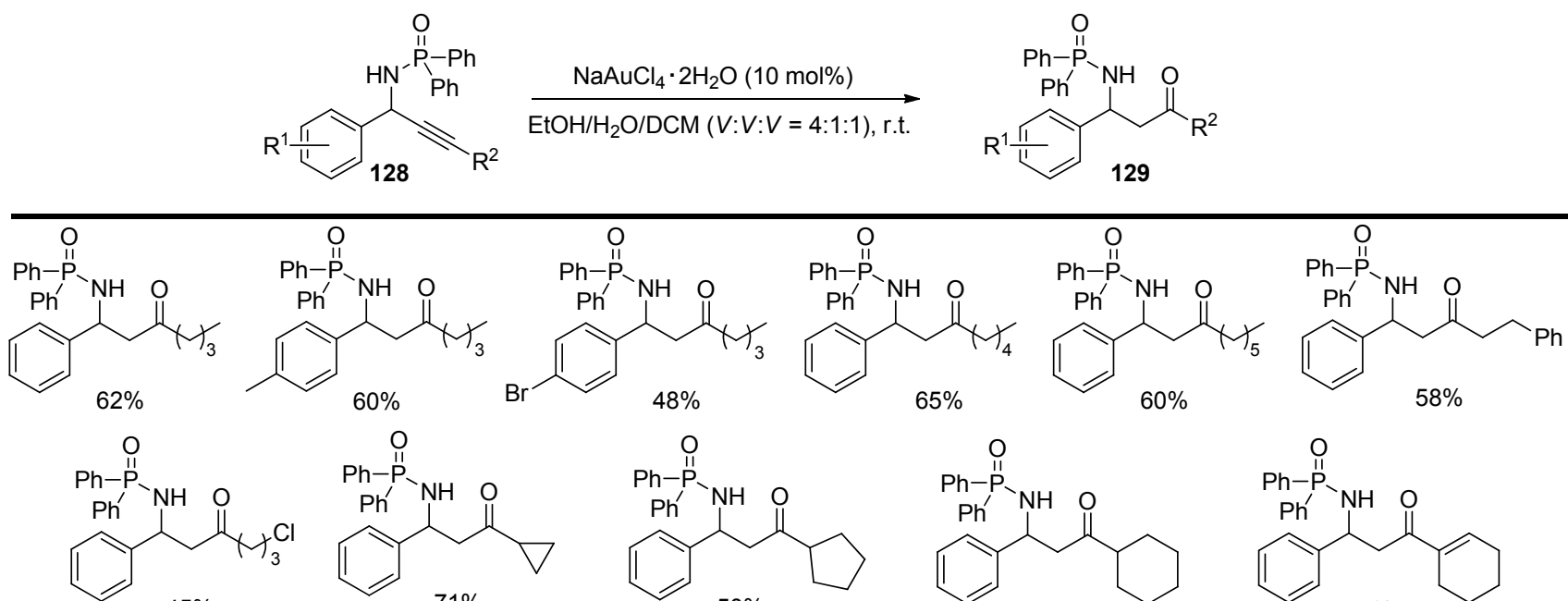

$50 \%$
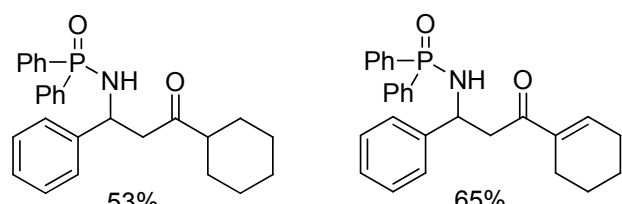<smiles>CCCCCC#C[C@@H](NP(=O)(c1ccccc1)c1ccccc1)c1ccccc1</smiles>

$85 \%$ ee

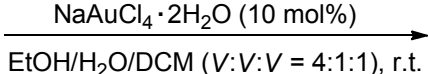

Ph- $\stackrel{\text { II }}{\text { P }}$

$\mathrm{Ph}^{\prime} \mathrm{NH}$<smiles>C=C(C[C](C)c1ccccc1)OCCCC</smiles>

$60 \%, 85 \%$ ee

图式 24 金催化炔丙胺与水的加成反应

Scheme $24 \mathrm{NaAuCl}_{4}$ catalyzed addition of propargyl amine with water

目前条件下，通过手性底物或手性辅基诱导合成或 者对对映异构体或非对映异构体进行结晶拆分或动力 
学拆分依然是最为行之有效的方法, 尤其是对于大规模 合成更甚. 鉴于当前的发展现状，1,3-氨基醇的不对称 合成研究还拥有广阔的空间, 设计活性更高、适用范围 更广、条件更温、选择性更好的催化剂会是当前及今后 研究的重点; 新型拆分剂或拆分方法的开发或许将有利 于手性 1,3-氨基醇的工业规模合成. 此外, 可回收型催 化剂的研究鲜有报道用于 1,3-氨基醇合成研究中, 或许 会是今后的一个研究热点.

\section{References}

[1] Bates, R. W.; Sa-Ei, K. Tetrahedron 2002, 58, 5957.

[2] Lait, S. M.; Rankic, D. A.; Keay, B. A. Chem. Rev. 2007, 107, 767.

[3] (a) Davis, F. A.; Gaspari, P. M.; Nolt, B. M.; Xu, P. J. Org. Chem. 2008, 73, 9619 .

(b) Shiro, Y.; Kato, K.; Fujii, M.; Ida, Y.; Akita, H. Tetrahedron 2006, 62, 8687 .

(c) Aschwanden, P.; Kværnø, L.; Geisser, R. W.; Kleinbeck, F.; Carreira, E. M. Org. Lett. 2005, 7, 5741.

(d) Keck, G. E.; Truong, A. P. Org. Lett. 2002, 4, 3131.

[4] Yao, C.-Z.; Xiao, Z.-F.; Ning, X.-S.; Liu, J.; Zhang, X.-W.; Kang, Y.-B. Org. Lett., 2014, 16, 5824 .

[5] Loh, T.-K.; Huang, J.-M.; Goh, S.-H.; Vittal, J. J. Org. Lett. 2000, 2, 1291.

[6] (a) Kochi, T.; Tang, T. P.; Ellman, J. A. J. Am. Chem. Soc. 2002, 124,6518 .

(b) Kochi, T.; Tang, T. P.; Ellman, J. A. J. Am. Chem. Soc. 2003, 125, 11276.

[7] Mackey, P.; Cano, R.; Foley, V. M.; McGlacken, G. P. Org. Synth. 2017, 94, 259.

[8] (a) Kennedy, A.; Nelson, A.; Perry, A. Synlett 2004, 967. (b) Fjelbey, K.; Svenstrup, N.; Püschl, A. Synthesis 2015, 47, 3231.

[9] Enders, D.; Moser, M.; Geibel, G.; Laufer, M. C. Synthesis 2004, 2040.

[10] List, B. J. Am. Chem. Soc. 2000, 122, 9336.

[11] (a) Córdova, A. Synlett 2003, 1651. (b) Córdova, A. Chem. Eur. J. 2004, 10, 1987.

[12] Westermann, B.; Neuhaus, C. Angew. Chem., Int. Ed. 2005, 44, 4077.

[13] Enders, D.; Grondal, C.; Vrettou, M.; Raabe, G. Angew. Chem., Int. Ed. 2005, 44, 4079.

[14] Fustero, S.; Jiménez, D.; Moscardó, J.; Catalán, S.; Pozo, C. Org. Lett. 2007, 9, 5283.

[15] Jha, V.; Kondekar, N. B.; Kumar, P. Org. Lett. 2010, 12, 2762.

[16] Millet, R.; Träff, A. M.; Petrus, M. L.; Bäckvall, J.-E. J. Am. Chem. Soc. 2010, 132, 15182.

[17] Chen, Y. K.; Yoshida, M.; MacMillan, D. W. C. J. Am. Chem. Soc. 2006, 128,9328 .

[18] Wenzel, A. G.; Jacobsen, E. N. J. Am. Chem. Soc. 2002, 124, 12964.

[19] Frías, M.; Carrasco, A. C.; Fraile, A.; Alemán, J. Chem.-Eur. J. 2017, 23, 3117.

[20] Josephsohn, N. S.; Snapper, M. L.; Hoveyda, A. H. J. Am. Chem.
Soc. 2004, 126, 3734.

[21] Matsunaga, S.; Yoshida, T.; Mornoto, H.; Kumagai, N.; Shibasaki, M. J. Am. Chem. Soc. 2004, 126, 8777.

[22] Trost, B. M.; Hung, C.-I.; Saget, T.; Gnanamani, E. Nat. Catal. 2018, 1,523

[23] (a) Espino, C. G.; When, P. M.; Chow, J.; Bois, J. D. J. Am. Chem. Soc. 2001, 123, 6935.

(b) Fiori, K. W; Espino, C. G.; Brodsky, B. H.; Bois, J. D. Tetrahedron 2009, 65, 3042.

[24] Fiori, K. W.; Fleming, J. J.; Bois, J. D. Angew Chem., Int. Ed. 2004, $43,4349$.

[25] Alderson, J. M.; Schomaker, J. M. Chem. Eur. J. 2017, 23, 8571.

[26] Zalatan, D. N.; Bois, J. D. J. Am. Chem. Soc. 2008, 130, 9220.

[27] Spreider, P. A.; Haydl, A.M.; Heinrich, M.; Breit, B. Angew. Chem. 2016, 128,15798

[28] Rice, G. T.; White, M. C. J. Am. Chem. Soc. 2009, 131, 11707.

[29] Qi, X.-B.; Rice, G. T.; Lall, M. S.; Plummer, M. S.; White, M. C. Tetrahedron 2010, 66, 4816.

[30] Nahra, E.; Liron, F.; Prestat, G.; Mealli, C.; Messaoudi, A.; Poli, G. Chem. Eur. J. 2009, 15, 11078.

[31] Xie, Y.-Z., Yu, K.; Gu, Z.-H. J. Org. Chem. 2014, 79, 1289.

[32] Ma, R.; Young, J.; Promontorio, R.; Dannheim, F. M.; Pattillo, C. C.; White, M. C. J. Am. Chem. Soc. 2019, 141, 9468.

[33] Paradine, S. M.; White, M. C. J. Am. Chem. Soc. 2012, 134, 2036.

[34] Ohno, H.; Hamaguchi, H.; Tanaka, T. J. Org. Chem. 2001, 66, 1867.

[35] Takemoto, Y.; Anzai, M.; Yanada, R.; Fujii, N.; Ohno, H.; Ibuka, T. Tetrahedron Lett. 2001, 42, 1725.

[36] Zhang, Y.-Q.; Bohle, F.; Bleith, R.; Schnakenburg, G.; Grimme, S.; Gansäuer, A. Angew. Chem. 2018, 130, 13716.

[37] Liu, J.; Wang, C. ACS Catal. 2020, 10, 556.

[38] Ghorai, M. K.; Das, K.; Kumar, A. Tetrahedron Lett. 2007, 48, 4373.

[39] Singh, A.; Sharma, B.; Sachdeva, D.; Mehra, V.; Singh, P.; Kumar, V. ChemistrySelect 2018, 3, 4764.

[40] Yao, C.-Z.; Xiao, Z.-F.; Liu, J.; Ning, X.-S.; Kang, Y.-B. Org. Lett. 2014, 16, 2498.

[41] Yao, C.-Z.; Xiao, Z.-F.; Ning, X.-S.; Liu, J.; Zhang, X.-W.; Kang, Y.-B. Org. Lett. 2014, 16, 5824.

[42] Xiao, Z.-F.; Yao, C.-Z.; Kang, Y.-B. Org. Lett. 2014, 16, 6512.

[43] Tiecco, M.; Testaferri, L.; Marini, F.; Sternativo, S.; Santi, C.; Bagnoli, L.; Temperini, A. Tetrahedron: Asymmetry 2001, 12, 3053.

[44] (a) Gais, H.-J.; Loo, R.; Das, P.; Raabe, G. Tetrahedron Lett. 2000, $41,2851$.

(b) Gais, Hans-Joachim; Loo, R.; Roder, D.; Das, P.; Raabe, G. Eur. J. Org. Chem. 2003, 1500.

[45] Murai, T.; Sano, H.; kawai, H.; Aso, H.; Shibahara, F. J. Org. Chem. 2005, 70, 8148 .

[46] Daniel, P. E.; Weber, A. E.; Malcolmson, S. J. Org. Lett. 2017, 19, 3490 .

[47] Geng, H.; Zhang W.; Chen, J.; Hou, G.; Zhou, L.; Zou, Y.; Wu, W.; Zhang, X. Angew. Chem., Int. Ed. 2009, 48, 6052.

[48] Xi, Y.; Butcher, T. W.; Zhang, J.; Hartwig, J. F. Angew. Chem., Int. Ed. 2016, 55, 776 .

[49] Ying, J.; Pu, L. J. Org. Chem. 2016, 81, 8135.

(Cheng, F.) 